\title{
Atuação do enfermeiro no manuseio do cateter venoso central de inserção Periférica em Unidade de Terapia Intensiva Neonatal
}

Nurses' performance in handling peripheral insertion central venous catheters in Neonatal

\author{
Intensive Care Units
}

Desempeño del enfermero en el manejo de catéteres venosos centrales de inserción periférica en Unidades de Cuidados Intensivos Neonatales

Marciele de Lima Silva

ORCID: https://orcid.org/0000-0003-2827-5316 Instituto de Educação Superior da Paraíba, Brasil E-mail: marcieledelsilva@gmail.com

Rayssa Stéfani Sousa Alves

ORCID: https://orcid.org/0000-0002-9666-675X

Pontifícia Universidade Católica de Goiás, Brasil E-mail: rayssastefani02@gmail.com

Bárbara Pereira Gomes

ORCID: https://orcid.org/0000-0002-0590-2228

Centro Universitário Unifacid, Brasil

E-mail: barbaraenfgomes@gmail.com

Reilda de Sá Lima

ORCID: https://orcid.org/0000-0002-3582-4232

Centro Universitário Santo Agostinho, Brasil E-mail: reilda_@hotmail.com

Maria Bianca e Silva Lima

ORCID: https://orcid.org/0000-0002-9175-0434

Centro Universitário Santo Agostinho, Brasil

E-mail: mariabianca10075@gmail.com

Juliana Torres Avelino

ORCID: https://orcid.org/0000-0002-8732-1856

Centro Universitário Santo Agostinho, Brasil

E-mail: Juliana_avelinno@hotmail.com

Ana Flávia Gomes de Lima

ORCID: https://orcid.org/0000-0002-0885-3003

Centro Universitário Santo Agostinho, Brasil

E-mail: anaflaviag17@gmail.com

Débora Alves de Assis

ORCID: https://orcid.org/0000-0003-0772-3079

Centro Universitário Santo Agostinho, Brasil

E-mail: deboraalvess_98@ @otmail.com

Laryce Steffane de Carvalho Borges ORCID: https://orcid.org/0000-0002-5303-2773

Centro Universitário Santo Agostinho, Brasil E-mail: Laryce.borges50@gmail.com

Jocilene Mesquita Batista

ORCID: https://orcid.org/0000-0003-0584-1645

Centro Universitário Santo Agostinho, Brasil E-mail: jocilenembs@gmail.com 


\author{
Keyla da Silva Ramos \\ ORCID: https://orcid.org/0000-0002-4392-6458 \\ Centro Universitário Santo Agostinho, Brasil \\ E-mail: silva.keylaa@gmail.com \\ Mariane Gomes Duarte de Sousa \\ ORCID: https://orcid.org/0000-0002-3218-9704 \\ Centro Universitário Santo Agostinho, Brasil \\ E-mail: duartemariane7@gmail.com \\ Raimunda da Silva Sousa Neta \\ ORCID: https://orcid.org/0000-0001-5927-0046 \\ Centro Universitário Santo Agostinho, Brasil \\ E-mail: raynettasousa@gmail.com \\ Laiana Dias Prudêncio \\ ORCID: https://orcid.org/0000-0002-0016-3868 \\ Centro Universitário Maurício de Nassau, Brasil \\ E-mail: laianadias568@gmail.com \\ Karla Cynthia dos Santos e Silva \\ ORCID: https://orcid.org/0000-0003-4080-0048 \\ Universidade Estadual da Paraíba, Brasil \\ E-mail: kcynthia7283@gmail.com \\ Layanne Cavalcante de Moura \\ ORCID: https://orcid.org/0000-0003-2781-1076 \\ Centro Universitário Unifacid, Brasil \\ E-mail: layannecavalcante@ hotmail.com \\ Joelma Maria dos Santos da Silva Apolinário \\ ORCID: https://orcid.org/0000-0001-9521-9432 \\ Faculdade Maurício de Nassau, Brasil \\ E-mail: jo.silva00@hotmail.com \\ Cicera Leiane Sampaio Rodrigues \\ ORCID: https://orcid.org/0000-0001-8038-1242 \\ Faculdade de Medicina Estácio Juazeiro do Norte, Brasil \\ E-mail: leianesampaio01@gmail.com \\ Moacir Andrade Ribeiro Filho \\ ORCID: https://orcid.org/0000-0003-1991-469X \\ Universidade Regional do Cariri, Brasil \\ E-mail: moacirarf@outlook.com \\ Jeferson Moreira dos Santos \\ ORCID: https://orcid.org/0000-0001-7807-1341 \\ Universidade do Estado da Bahia, Brasil \\ E-mail: Jeff.ibce73@gmail.com \\ Geovanna Carey Brabo da Silva \\ ORCID: https://orcid.org/0000-0001-5539-4666 \\ Universidade da Amazônia, Brasil \\ E-mail: eunannamathias@gmail.com
}

\title{
Resumo
}

Analisar as evidências científicas sobre a atuação do enfermeiro no manuseio do Cateter Venoso Central de Inserção Periférica em Unidade de Terapia Intensiva Neonatal. O presente estudo trata de uma revisão bibliográfica do método revisão integrativa da literatura, realizado nos meses entre outubro de 2020 a fevereiro de 2021 . A busca efetuou-se, através da Plataforma da Biblioteca Virtual em Saúde - BVS, utilizando as bases de dados Literatura LatinoAmericana e do Caribe em Ciências da Saúde (LILACS), Base de Dados de Enfermagem (BDENF), e por meio da Biblioteca Eletrônica da Saúde - Scientific Electronic Library Online (SCIELO). Aderindo-se através dos descritores/palavras chaves: "Cuidados de Enfermagem", "Unidades de Terapia Intensiva Neonatal", "Cateterismo Venoso Central", "Cateterismo Periférico", combinados com o operador booleano "AND”. As principais indicações para uso do PICC são os recém-nascidos que necessitem de terapia intravenosa por um período superior a seis dias, utilização de medicações (principalmente antibióticos, quimioterápicos, soluções vesicantes e hiperosmolares), nutrição parenteral prolongada ou outras terapias intravenosas de longa permanência. A utilização do PICC, é uma inovada tecnologia necessária em neonatalogia, está se tornando um procedimento comum a prática dos enfermeiros nas unidades de alto risco neonatal. Para isto, o manuseio deste dispositivo requer conhecimento, destreza e habilidade, priorizando o cuidado com a manutenção do cateter. Diante desse contexto, destaca-se a necessidade do PICC ser a via de primeira escolha para terapia intravenosa, com vistas à minimização do estresse e dor ao neonato, à diminuição do número de punções venosas e ao estabelecimento de um acesso duradouro e de fácil manuseio, reconhecendo potencialidades acerca do uso do dispositivo.

Palavras-chave: Cuidados de enfermagem; Unidades de terapia intensiva neonatal; Cateterismo venoso central; Cateterismo periférico. 


\begin{abstract}
To analyze the scientific evidence on the role of nurses in the handling of the peripherally inserted central venous catheter in a neonatal intensive care unit. The present study deals with a bibliographic review of the integrative literature review method, carried out between October 2020 and February 2021. The search was carried out, through the Virtual Health Library Platform - VHL, using the Literature databases Latin American and Caribbean Health Sciences (LILACS), Nursing Database (BDENF), and through the Electronic Health Library - Scientific Electronic Library Online (SCIELO). Adhering to the keywords / keywords: "Nursing Care", "Neonatal Intensive Care Units", "Central Venous Catheterization", "Peripheral Catheterization", combined with the Boolean operator "AND". The main indications for using PICC are newborns who need intravenous therapy for more than six days, use of medications (mainly antibiotics, chemotherapy, vesicating and hyperosmolar solutions), prolonged parenteral nutrition or other long-term intravenous therapies. The use of PICC, one of which is an innovative technology needed in neonatalogy, is becoming a common procedure for nurses in high-risk neonatal units. For this, the handling of this device requires knowledge, dexterity and skill, prioritizing care with the maintenance of the catheter. In this context, the need for PICC to be the first choice route for intravenous therapy is highlighted, with a view to minimizing stress and pain to the neonate, reducing the number of venipunctures and establishing a long-term and easy-to-handle access. , recognizing potentialities regarding the use of the device.
\end{abstract}

Keywords: Nursing care; Neonatal intensive care units; Central venous catheterization; Peripheral catheterization.

\title{
Resumen
}

Analizar la evidencia científica sobre el papel del enfermero en el manejo del catéter venoso central de inserción periférica en una unidad de cuidados intensivos neonatales. El presente estudio trata de una revisión bibliográfica del método de revisión integradora de la literatura, realizada entre octubre de 2020 y febrero de 2021. La búsqueda se realizó, a través de la Plataforma de Biblioteca Virtual en Salud - BVS, utilizando las bases de datos de literatura de Ciencias de la Salud de América Latina y el Caribe ( LILACS), Base de Datos de Enfermería (BDENF), y a través de la Biblioteca Electrónica en Salud - Biblioteca Electrónica Científica en Línea (SCIELO). Adhiriéndose a las palabras clave / palabras clave: "Atención de enfermería", "Unidades de cuidados intensivos neonatales", "Cateterismo venoso central", "Cateterismo periférico", combinado con el operador booleano "Y". Las principales indicaciones para el uso de PICC son los recién nacidos que necesitan terapia intravenosa durante más de seis días, uso de medicamentos (principalmente antibióticos, quimioterapia, soluciones vesicantes e hiperosmolares), nutrición parenteral prolongada u otras terapias intravenosas de larga duración. El uso de PICC, una de las cuales es una tecnología innovadora necesaria en neonatología, se está convirtiendo en un procedimiento común para las enfermeras en las unidades neonatales de alto riesgo. Para ello, el manejo de este dispositivo requiere conocimiento, destreza y habilidad, priorizando el cuidado con el mantenimiento del catéter. En este contexto, se destaca la necesidad de que el PICC sea la vía de primera elección para la terapia intravenosa, con el fin de minimizar el estrés y el dolor del neonato, reducir el número de venopunciones y establecer una vía de acceso a largo plazo y fácil, reconociendo las potencialidades. con respecto al uso del dispositivo.

Palabras clave: Cuidado de enfermera; Unidades de cuidados intensivos neonatales; Cateterismo venoso central; Cateterismo periférico.

\section{Introdução}

O Cateter Central de Inserção Periférica (PICC) é um dispositivo comum empregado na terapia intravenosa de neonatos que dependem da necessidade de administração de drogas vasoativas, hiperosmolares, antibióticos e nutrição parenteral e exige a manutenção de um acesso venoso seguro e duradouro. Usado com esta finalidade pode contribuir para um aumento da taxa de sobrevivência de bebês prematuros e gravemente doentes internados em Unidade de Terapia Intensiva Neonatal (UTIN) (Bomfim, Passos, Santos, Santos, \& Silva, 2019).

O Cateter Venoso Central de Inserção Periférica, vem sendo utilizado como alternativa de acesso venoso estável e eficaz para neonatos. Entretanto sua inserção envolve um procedimento de alta complexidade que exige conhecimentos específicos. A utilização do PICC tem como finalidade a promoção da terapia intravenosa por tempo prolongado e de forma segura, preservando a rede venosa periférica, além de diminuir a dor e estresse de repetidas punções. É indicado nos casos que exigem acesso venoso por período superior a seis dias e administração de soluções hipertônicas e/ou vesicantes, como nutrição parenteral total (osmolaridade acima de $600 \mathrm{mlOsmol} / \mathrm{L}$ ou soro glicosado com concentração superior a 12,5\%). Sua indicação exige perícia, técnica, capacidade de julgamento clínico e tomada de decisão consciente, segura e eficaz por parte do profissional de saúde (Ferreira et al., 2020). 
Quando se relaciona PICC ao cuidado do neonato em UTIN, destacam-se algumas particularidades que envolvem tanto o recém-nascido quanto o procedimento, devido a características singulares que podem influenciar de forma significativa na eficácia do uso deste dispositivo, devendo o profissional ter consciência da responsabilidade do procedimento. Assim, o enfermeiro é um dos principais responsáveis pela avaliação da indicação do PICC, bem como de sua inserção, acompanhamento e avaliação. Este profissional tem papel fundamental na prevenção das complicações, fator essencial para a reabilitação do $\mathrm{RN}$ e o sucesso no tratamento. Vale destacar que a terapia intravenosa deve ser iniciada com o objetivo de prestar uma assistência ótima aos neonatos, com propriedade e capacidade de aumentar o sucesso na obtenção do acesso venoso, priorizando a segurança do paciente, com redução dos danos físicos, psicológicos e dos eventos adversos, buscando aumento da satisfação com o cuidado e assistência da equipe (Ferreira et al., 2020).

Segundo Prado et al. (2019), o PICC, utilizado em larga escala nos serviços de pediatria e neonatologia, estabelece um acesso intravenoso seguro para a administração de medicamentos e nutrição que sustentam a vida. Este dispositivo pode ser inserido à beira leito e permanecer no sítio por várias semanas. Além disso, apresenta baixo custo, contribui para a qualidade de vida e reduz a dor física e psicológica.

A inserção do PICC consiste em sua introdução por meio de uma veia superficial ou profunda da extremidade, condução até o terço distal da veia cava superior ou proximal da veia cava inferior, e confirmação de sua localização por meio de radiografia. O procedimento é realizado, exclusivamente, por enfermeiro ou médico habilitados. É importante ressaltar que o RN com PICC apresenta várias necessidades, entre elas um acesso venoso seguro que garanta que a terapêutica medicamentosa seja realizada, o que irá contribuir no atendimento das necessidades nutricionais, imunológicas e de hidratação. Verifica-se, assim, a importância de se manter a integridade do cateter, a fim de evitar complicações hospitalares, tais como infecções da corrente sanguínea, lesões de pele e perdas acidentais (Prado et al., 2019).

O Cateter de Acesso Venoso Central por Inserção Periférica é amplamente utilizado em neonatos, devido vantagens como o tempo de permanência prolongado, redução do número de punção, menor risco de flebite, infiltração e extravasamento. A inserção do PICC é uma atividade de enfermeiros e médicos capacitados. No cenário atual o enfermeiro é responsável por capacitar a equipe de enfermagem em relação às recomendações para manuseio e manutenção do dispositivo, bem como identificar precocemente os sinais e sintomas associados às complicações mecânicas, trombóticas e infecciosas (Silva, 2019).

A inserção, a manutenção e o controle da infecção do cateter central de inserção periférica requerem práticas assistenciais que promovam a segurança do paciente, com menor exposição à dor, bem como redução de riscos e complicações inerentes ao procedimento. Neste sentido, entender os processos que envolvem a inserção do cateter central de inserção periférica e a avaliação de práticas de manutenção pela enfermagem, em Unidades de Terapia Intensiva Neonatais, podem fornecer estratégias para boas práticas e melhores resultados no cuidado de recém-nascidos em uso do cateter, evitando intercorrências e remoção precoce do cateter (Baggio, Cheffer, Luz, Sanches, \& Berres, 2019).

Nas Unidades de Cuidados Intensivos Neonatais a utilização do CCIP tem se tornado um exercício frequente, sendo os enfermeiros os profissionais responsáveis por sua inserção, manutenção e remoção. Assim, cada vez mais, os enfermeiros buscam capacitar-se para essa prática. Apesar dos inúmeros benefícios atribuídos ao CCIP, os profissionais devem estar atentos aos riscos relacionados ao seu uso, associados a algumas complicações que podem ocorrer na inserção, durante a manutenção e a remoção. Tais complicações ocorrem por problemas mecânicos como obstrução, ruptura do cateter, perfuração do vaso, extravasamento, trombose, problemas infecciosos, sepse relacionada ao cateter, hematoma, posição inadequada do cateter e pneumotórax (Swerts, Felipe, Rocha, \& Andrade, 2013).

Segundo Dórea, Castro, Costa, Kimura, \& Santos (2011), o CCIP é indicado para terapêutica parenteral prolongada e a vantagem de seu uso é ser mais seguro para infusão de soluções vesicantes, causando menor estresse, desconforto e redução da frequência de exposição à punção venosa, além do menor custo em relação ao cateter venoso central inserido 
cirurgicamente. O cateter venoso central (CVC) tuneilizado ou cirurgicamente inserido é associado a maior taxa de infecção comparado ao CCIP. Durante a instalação e manutenção do CCIP, as práticas de enfermagem adquirem importância como estratégia de segurança ao paciente por influenciarem na ocorrência de complicações e consequente remoção não eletiva.

A indicação do uso do PICC é para pacientes que necessitam de acesso venoso prolongado, principalmente se este for submetido à nutrição parenteral total, infusão de drogas vesicantes contínuas, antibioticoterapia, soluções hipertônicas, presença de distúrbios de coagulação e necessidade de medidas de PVC (pressão venosa central). Dessa forma, O uso do PICC apresenta importantes vantagens, dentre as quais se destaca: terapia de média e longa duração com múltiplos locais de inserção; via confiável de nutrição parenteral, fármacos e soluções irritantes e vesicantes; menor risco de infecção; redução do desconforto para o recém-nascido; maior acesso dos pais ao recém-nascido e redução do número de punções com consequente diminuição de procedimentos dolorosos, estresse e manipulação do neonato (Motta, Fialho, Dias, \& Nascimento, 2011).

A facilidade de punção do PICC, reflete na sua utilização em larga escala nas UTIN, somada também ao tempo de permanência prolongado, inserção menos traumática e risco reduzido de complicações. O fino calibre dos cateteres e a utilização de uma técnica de inserção a partir de vasos periféricos contribuem para que sejam menos invasivos e, consequentemente, ofereçam menor risco aos neonatos no momento da introdução, se comparados aos dispositivos inseridos cirurgicamente e em vasos mais calibrosos. No entanto, o PICC requer profissional treinado para sua inserção e cuidados diários de manutenção, visando prevenir complicações. Assim, o enfermeiro capacitado e com conhecimento técnico-científico deve realizar a manutenção diária do cateter PICC, para obter o sucesso desse acesso, seguindo alguns cuidados de enfermagem como: inserção e localização correta do cateter, manutenção da permeabilidade, troca de curativos na técnica asséptica, vigilância de infecções, infiltrações e outras intercorrências relacionadas à permeabilidade, identificação de complicações, infusão de solução prescrita (Cavalcante et al., 2015).

A enfermagem a ciência que dedica-se ao cuidado do ser humano em todas as suas fases de vida, destaca-se importância destes profissionais nos cuidados dispensados ao neonatos em UTI. O enfermeiro tem competência técnica e legal para inserir e manipular o PICC, amparado no Brasil pela Resolução no 258/2001, do Conselho Federal de Enfermagem (COFEN), qualificado e/ou capacitado profissionalmente. Considerando a relevância do enfermeiro como sendo um dos principais responsáveis pela indicação, inserção, manutenção e retirada do cateter central de inserção periférica (Vera, Sousa, \& Araújo, 2015).

Nesse contexto, os cuidados de enfermagem são de grande importância na manutenção do PICC e prevenção de infecções. Primeiramente a escolha do local onde será inserido o cateter, manutenção e remoção deles dependem do sucesso da utilização do PICC, evitando infecções e perdas, deve-se atentar também ao peso do RN inferior a 2.500 gramas e duração de uso em dias do mesmo em RN internados em uma Unidade de Terapia Intensiva (Barros, Santos, \& Jordao, 2019).

Diante da temática em discussão, foi elaborada a seguinte questão norteadora do estudo: "Qual a atuação do enfermeiro no manuseio do Cateter Venoso Central de Inserção Periférica em Unidade de Terapia Intensiva Neonatal"? Assim, o objetivo do presente estudo é analisar as evidências científicas sobre a atuação do enfermeiro no manuseio do Cateter Venoso Central de Inserção Periférica em Unidade de Terapia Intensiva Neonatal.

A realização do estudo relacionado à temática, é essencial para a construção coletiva do conhecimento, pois, o estudo possibilita a sociedade acadêmica e cientifica a ampliar o conhecimento sobre a atuação do enfermeiro no manuseio do Cateter Venoso Central de Inserção Periférica em Unidade de Terapia Intensiva Neonatal. Desse modo, o estudo trará contribuições importantes para a comunidade científica e para a sociedade, na medida em que acrescentará as evidências científicas discussões relevantes a respeito dessa temática. Desta forma, acredita-se que o reconhecimento da importância do cuidado na manutenção do cateter pode contribuir para o estabelecimento de procedimentos que qualifiquem a assistência da equipe de enfermagem, fornecendo uma prática clínica baseada em evidências científicas. 


\section{Metodologia}

O presente estudo trata de uma revisão bibliográfica do método revisão integrativa da literatura, realizado nos meses entre outubro de 2020 a fevereiro de 2021. Sendo uma ferramenta de investigação que permite à procura, a avaliação crítica e a síntese das evidências disponíveis sobre o tema investigado, em que o produto final é o estado do conhecimento, a implementação de intervenções efetivas na prestação de cuidados e na redução de custos. Além disso, permite a identificação de fragilidades, que poderão conduzir ao desenvolvimento de futuras investigações (Sousa, Marques-Vieira, Severino, \& Antunes, 2017).

A revisão configura-se, portanto, como um tipo de revisão da literatura que reúne achados de estudos desenvolvidos mediante diferentes metodologias, permitindo aos revisores sintetizar resultados sem ferir a filiação epistemológica dos estudos empíricos incluídos. Para que esse processo concretize-se de maneira lógica, isenta de desatinos epistemológicos, a revisão requer que os revisores procedam à análise e à síntese dos dados primários de forma sistemática e rigorosa (Soares et al., 2014).

O processo de revisão da literatura requer a elaboração de uma síntese pautada em diferentes tópicos, capazes de criar uma ampla compreensão sobre o conhecimento. A revisão da literatura é um primeiro passo para a construção do conhecimento científico, pois é através desse processo que novas teorias surgem, bem como são reconhecidas lacunas e oportunidades para o surgimento de pesquisas num assunto específico (Botelho, Cunha, \& Macedo, 2011).

A revisão integrativa permite que o leitor reconheça os profissionais que mais investigam determinado assunto, separar o achado científico de opiniões e ideias, além de descrever o conhecimento no seu estado atual, promovendo impacto sobre a prática clínica. Este método de pesquisa proporciona aos profissionais de saúde dados relevantes de um determinado assunto, em diferentes lugares e momentos, mantendo-os atualizados e facilitando as mudanças na prática clínica como consequência da pesquisa. Dessa forma, acreditamos que a revisão integrativa é uma ferramenta importante no processo de comunicação dos resultados de pesquisas, facilitando a utilização desses na prática clínica, uma vez que proporciona uma síntese do conhecimento já produzido e fornece subsídios para a melhoria da assistência à saúde (Mendes, Silveira, \& Galvão, 2008). 
Figura 1. Fluxograma das fases distintas da revisão integrativa.

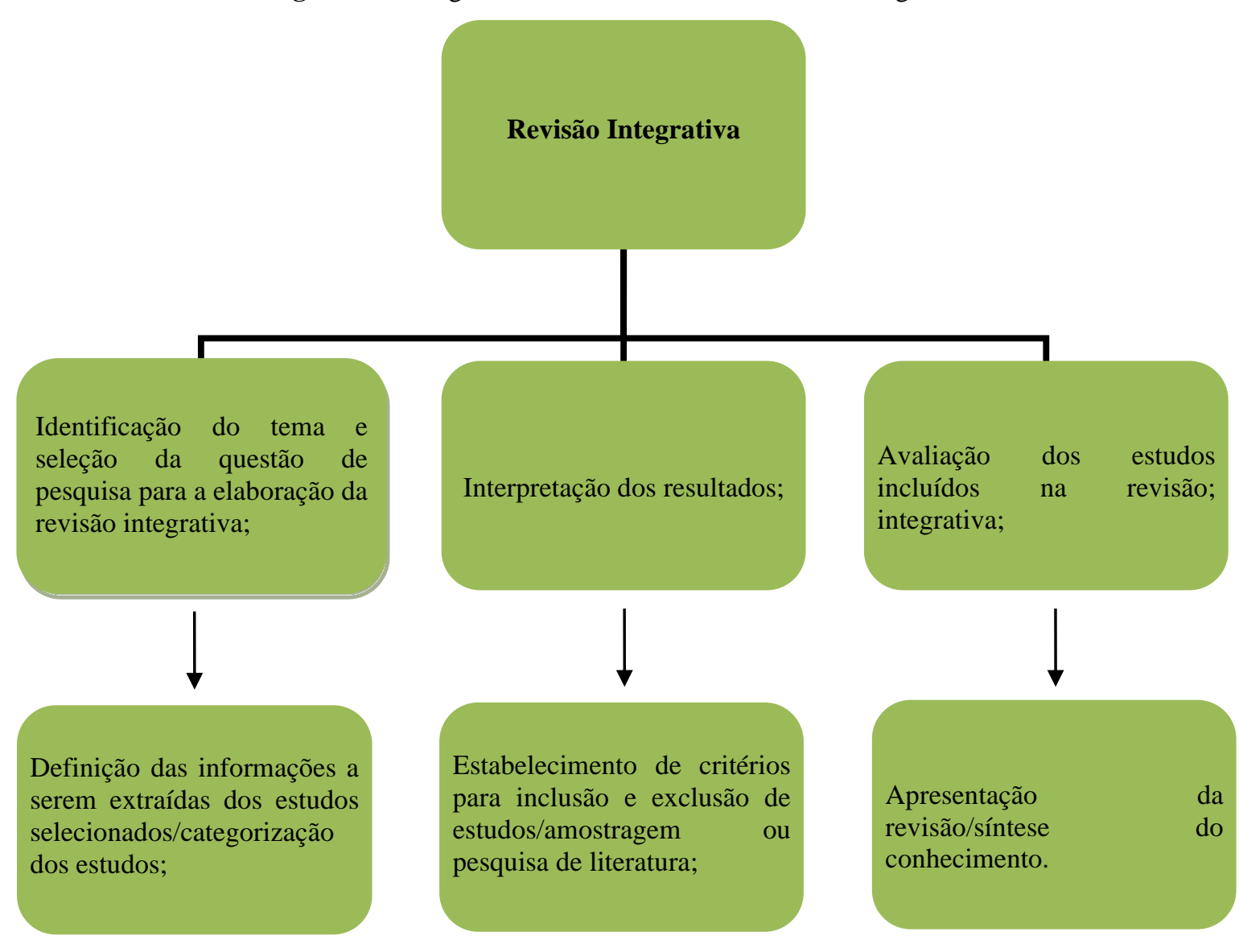

Fonte: Mendes, Silveira, \& Galvão, 2008.

A revisão integrativa é um tipo de pesquisa que fornece informações mais amplas de maneira sistemática, ordenada e abrangente, sobre um assunto ou tema, com a finalidade de sintetizar resultados obtidos em pesquisa sobre temas ou questões. A definição das informações a serem extraídas dos estudos selecionados por categorização; avaliação dos estudos incluídos; interpretação dos resultados; e apresentação da revisão/síntese do conhecimento (Ercole, Melo, \& Alcoforado, 2015).

Estudo elaborado com abordagem qualitativa tornando-se importante a interpretação por parte do pesquisador com suas opiniões sobre o fenômeno em estudo. Neste tipo de pesquisa destacam-se algumas características como: a pesquisa qualitativa, em geral, ocorre no ambiente natural com coleta direta de dados e o pesquisador é o principal instrumento; os dados coletados são preferencialmente descritivos; a preocupação do processo é predominante em relação à do produto; a análise de dados e informações tende a seguir um processo indutivo (Pereira, Shitsuka, Parreira, \& Shitsuka, 2018).

De acordo com Souza, Silva, e Carvalho (2010), a ser realizada nas seguintes etapas: 1- Elaboração da pergunta norteadora; 2- Busca nas bases de dados e amostragem; 3- Coleta de dados, 4- Análise crítica.

Para responder à questão norteadora do estudo: "Qual a assistência de enfermagem no manuseio do Cateter Venoso Central de Inserção Periférica em Unidade de Terapia Intensiva"? Aplicou-se os descritores/palavras-chaves: "Cuidados de Enfermagem", "Unidades de Terapia Intensiva Neonatal", "Cateterismo Venoso Central", "Cateterismo Periférico".

A busca efetuou-se, através da Plataforma da Biblioteca Virtual em Saúde - BVS, utilizando as bases de dados Literatura Latino-Americana e do Caribe em Ciências da Saúde (LILACS), Base de Dados de Enfermagem (BDENF), e por meio da Biblioteca Eletrônica da Saúde - Scientific Electronic Library Online (SCIELO). Aderindo-se através dos descritores/palavras chaves: "Cuidados de Enfermagem", "Unidades de Terapia Intensiva Neonatal", "Cateterismo Venoso Central", "Cateterismo Periférico", combinados com o operador booleano "AND". 
Os critérios de inclusão estabelecidos foram: artigos originais disponibilizados na íntegra, completos, que abrangessem a temática e na forma online, publicados nos idioma português, inglês e espanhol, publicações que respondiam a questão norteadora do estudo. Os critérios de exclusão estabelecidos na seleção foram: artigos incompletos, artigos duplicados, teses, dissertações, monografias e manuais. No início da pesquisa obteve-se 5845 publicações, após a aplicação dos critérios de inclusão e exclusão totalizou-se parcialmente 831 artigos, depois de uma leitura mais precisa aderiu-se um total final de 33 publicações de acordo para serem trabalhadas no estudo.

O fluxograma representado abaixo, caracteriza a estratégia de coleta de dados utilizada pelos autores, no sentido de detalhar as principais evidencias encontradas no estudo.

Figura 2. Fluxograma da Estratégia de Busca - Bases de Dados, Teresina-PI, Brasil, 2021.

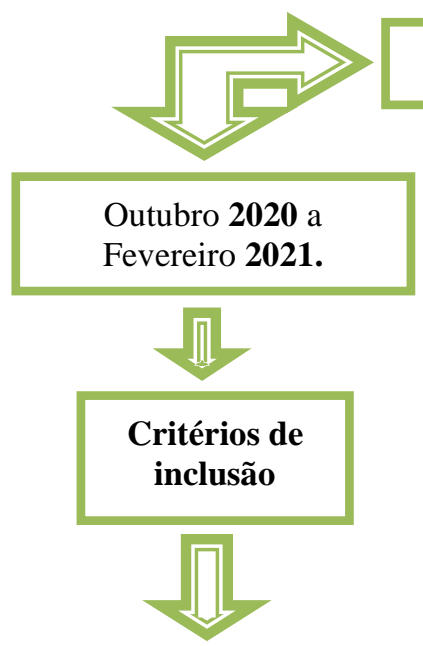

Artigos originais disponibilizados na íntegra, completos, que abrangessem a temática e na forma online, publicados nos idioma português, inglês e espanhol, publicações que respondiam a questão norteadora do estudo.

\section{Estratégia de Busca Revisão Integrativa}

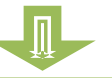

\section{Critérios de exclusão}

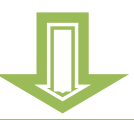

Artigos incompletos, artigos duplicados, teses, dissertações, monografias e manuais.

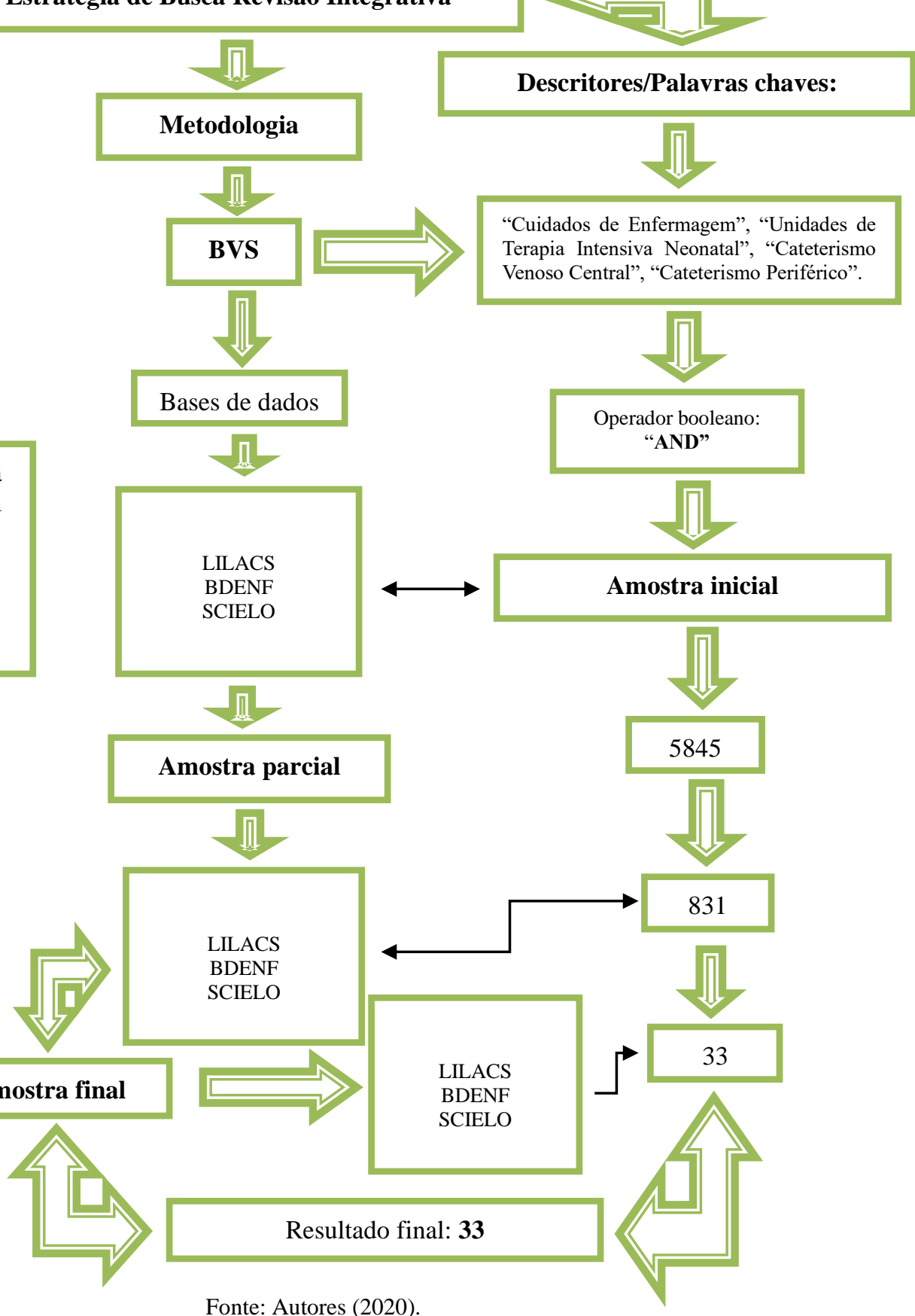


No Fluxograma 2, estão expostos, a estratégia de busca, bases de dados, período de realização do estudo, critérios de inclusão e exclusão, amostra inicial, parcial e final, de acordo com a quantidade de artigos que irão compor os resultados do estudo.

O presente estudo assegura os aspectos éticos, garantindo a autoria dos artigos pesquisados, utilizando para as citações e referências dos autores as normas APA. Os preceitos éticos estabelecidos no que se refere a zelar pela legitimidade das informações, privacidade e sigilo das informações, quando necessárias, tornando os resultados desta pesquisa públicos. Os pesquisadores buscaram a legitimidade e fidelidade nas citações dos autores seja nas citações diretas ou parafraseadas no estudo.

\section{Resultados e Discussão}

Diante dos resultados obtidos no estudo por meio da estratégia de busca, os autores delinearam variáveis para melhor descrever as evidências encontradas na pesquisa. O quadro a seguir caracteriza os artigos com base nas variáveis propostas: número do artigo, periódico, base de dados, autor e ano de publicação, título, objetivo, resultados em evidências e conclusões importantes.

Quadro 1 - Caracterização dos artigos da pesquisa.

\begin{tabular}{|c|c|c|c|c|c|c|c|}
\hline $\mathbf{N}$ & $\begin{array}{l}\text { Perió - } \\
\text { dico }\end{array}$ & $\begin{array}{l}\text { Bases } \\
\text { de } \\
\text { Dados }\end{array}$ & $\begin{array}{l}\text { Autor e } \\
\text { Ano }\end{array}$ & Título & $\begin{array}{l}\text { Tipo de } \\
\text { Estudo }\end{array}$ & Objetivo & $\begin{array}{l}\text { Resultados em evidências e } \\
\text { conclusões importantes }\end{array}$ \\
\hline 1 & $\begin{array}{l}\text { Rev } \\
\text { Esc } \\
\text { Enferm } \\
\text { USP. }\end{array}$ & $\begin{array}{l}\text { LILA } \\
\text { CS }\end{array}$ & $\begin{array}{l}\text { Costa et } \\
\text { al., } 2020 .\end{array}$ & $\begin{array}{lr}\text { Bundle de } & \text { Cateter } \\
\text { Venoso } & \text { Central: } \\
\text { conhecimento } & \mathrm{e} \\
\text { comportamento } & \mathrm{de} \\
\text { profissionais } & \text { em } \\
\text { Unidades de Terapia } \\
\text { Intensiva adulto. }\end{array}$ & $\begin{array}{c}\text { Estudo } \\
\text { transversal, } \\
\text { descritivo, } \\
\text { quantitativo. }\end{array}$ & $\begin{array}{lr}\text { Avaliar } & \text { o } \\
\text { conhecimento } & \mathrm{e} \\
\text { comportamento } & \text { dos } \\
\text { profissionais de } & \text { UTI } \\
\text { quanto às ações } \\
\text { recomendadas } \\
\text { bundle de prevenção } \\
\text { de infecção de } \\
\text { corrente sanguínea } \\
\text { relacionada ao cateter } \\
\text { venoso central. }\end{array}$ & $\begin{array}{l}\text { A realização de treinamentos e programas de } \\
\text { educação permanente para todos os } \\
\text { profissionais de saúde engajados na inserção } \\
\text { e manutenção do CVC é imprescindível para } \\
\text { prevenir a infecção de corrente sanguínea } \\
\text { associada a esse dispositivo. O diagnóstico } \\
\text { sobre o conhecimento e comportamento da } \\
\text { equipe torna-se necessário para } \\
\text { implementação de ações e determinação de } \\
\text { estratégias mais assertivas em prol da } \\
\text { segurança do paciente internado na UTI em } \\
\text { uso de CVC. }\end{array}$ \\
\hline 2 & $\begin{array}{l}\text { Rev } \\
\text { Baiana } \\
\text { Enferm }\end{array}$ & $\begin{array}{l}\text { LILA } \\
\text { CS }\end{array}$ & $\begin{array}{c}\text { Mittang, } \\
\text { Stiegler, } \\
\text { Kroll, \& } \\
\text { Schultz, } \\
2020 .\end{array}$ & $\begin{array}{l}\text { Cateter central de } \\
\text { inserção periférica em } \\
\text { recém-nascidos:fatores } \\
\text { de retirada. }\end{array}$ & $\begin{array}{l}\text { Estudo } \\
\text { retrospectivo, } \\
\text { documental, } \\
\text { transversal } \\
\text { quantitativo. }\end{array}$ & $\begin{array}{l}\text { Identificar } \text { os } \\
\text { principais fatores de } \\
\text { retirada do cateter } \\
\text { central de inserção } \\
\text { periférica em recém- } \\
\text { nascidos em unidade } \\
\text { de terapia intensiva } \\
\text { neonatal e verificar a } \\
\text { associação de } \\
\text { variáveis do recém - } \\
\text { nascido e do cateter } \\
\text { com os fatores de } \\
\text { retirada. }\end{array}$ & $\begin{array}{l}\text { As principais indicações para uso do PICC } \\
\text { são os recém-nascidos que necessitem de } \\
\text { terapia intravenosa por um período superior } \\
\text { a seis dias, utilização de medicações } \\
\text { (principalmente } \\
\text { quimioterápicos, soluções vesicantes e } \\
\text { hiperosmolares), nutrição parenteral prolon- } \\
\text { gada ou outras terapias intravenosas de longa } \\
\text { permanência. Os benefícios são a longa } \\
\text { permanência do dispositivo, redução da } \\
\text { ocorrência de pneu motórax e hemotórax, } \\
\text { custo financeiro inferior ao do cateter venoso } \\
\text { central inserido cirurgicamente, redução do } \\
\text { número de punções venosas periféricas e, } \\
\text { consequentemente, otimização do tempo do } \\
\text { profissional de enfermagem. }\end{array}$ \\
\hline 3 & $\begin{array}{c}\text { Rev } \\
\text { Eletr } \\
\text { Enferm }\end{array}$ & $\begin{array}{l}\text { LILA } \\
\text { CS }\end{array}$ & $\begin{array}{l}\text { Ferreira } \\
\text { et al. } \\
2020 .\end{array}$ & $\begin{array}{l}\text { A utilização de } \\
\text { cateteres venosos } \\
\text { centrais de inserção } \\
\text { periférica na Unidade } \\
\text { Intensiva Neonatal. }\end{array}$ & $\begin{array}{l}\text { Estudo } \\
\text { retrospectivo, } \\
\text { descritivo e } \\
\text { quantitativo. }\end{array}$ & $\begin{array}{l}\text { Analisar a utilização } \\
\text { dos cateteres centrais } \\
\text { de inserção periférica } \\
\text { em recém-nascidos } \\
\text { internados na Unidade } \\
\text { de Terapia Intensiva } \\
\text { Neonatal. }\end{array}$ & $\begin{array}{l}\text { Quando se relaciona PICC ao cuidado do } \\
\text { neonato em UTIN, destacam-se algumas } \\
\text { particularidades que envolvem tanto o } \\
\text { recém-nascido quanto o procedimento, } \\
\text { devido a características singulares que } \\
\text { podem influenciar de forma significativa na } \\
\text { eficácia do uso deste dispositivo, devendo o } \\
\text { profissional ter consciência da } \\
\text { responsabilidade do procedimento. Assim, o } \\
\text { enfermeiro é um dos principais responsáveis } \\
\text { pela avaliação da indicação do PICC, bem } \\
\text { como de sua inserção, acompanhamento e } \\
\text { avaliação. Este profissional tem papel } \\
\text { fundamental na prevenção das complicações, } \\
\text { fator essencial para a reabilitação do RN e o } \\
\text { sucesso no tratamento. }\end{array}$ \\
\hline
\end{tabular}




\begin{tabular}{|c|c|c|c|c|c|c|c|}
\hline 4 & $\begin{array}{l}\text { Rev } \\
\text { Enferm } \\
\text { UERJ. }\end{array}$ & $\begin{array}{l}\text { LILA } \\
\text { CS }\end{array}$ & $\begin{array}{c}\text { Prado et } \\
\text { al., } 2019 .\end{array}$ & $\begin{array}{l}\text { Necessidades humanas } \\
\text { básicas alteradas em } \\
\text { neonatos com cateter } \\
\text { central de inserção } \\
\text { periférica. }\end{array}$ & $\begin{array}{c}\text { Estudo } \\
\text { transversal } \\
\text { quantitativo. }\end{array}$ & $\begin{array}{l}\text { Identificar as } \\
\text { necessidades humanas } \\
\text { básicas alteradas nos } \\
\text { neonatos com cateter } \\
\text { central de inserção } \\
\text { periférica em Unidade } \\
\text { de Terapia Intensiva } \\
\text { Neonatal, à luz da } \\
\text { Teoria } \\
\begin{array}{l}\text { Necessidades Huma- } \\
\text { nas Básicas. }\end{array}\end{array}$ & $\begin{array}{l}\text { Enfermagem aos recém-nascidos com PICC, } \\
\text { por contribuir com o enfermeiro para a } \\
\text { elaboração de um plano de cuidados } \\
\text { específico, direcionar as intervenções, } \\
\text { aumentar a qualidade de vida desses } \\
\text { neonatos e a visibilidade da enfermagem } \\
\text { enquanto ciência. Além disso, a partir do } \\
\text { conhecimento de tais respostas humanas, } \\
\text { torna-se possível predizer e detectar as } \\
\text { potenciais complicações. }\end{array}$ \\
\hline 5 & $\begin{array}{c}\text { Cuid } \\
\text { Enferm }\end{array}$ & $\begin{array}{l}\text { LILA } \\
\text { CS }\end{array}$ & $\begin{array}{l}\text { Bomfim, } \\
\text { Passos, } \\
\text { Santos, } \\
\text { Santos, \& } \\
\text { Silva, } \\
2019 . \\
\end{array}$ & $\begin{array}{lr}\text { Desafios } & \text { na } \\
\text { manutenção do cateter } \\
\text { central de inserção } \\
\text { periférica r } \\
\text { neonatos. }\end{array}$ & $\begin{array}{c}\text { Estudo } \\
\text { qualitativo. }\end{array}$ & $\begin{array}{l}\text { Relatar desafios e } \\
\text { estratégia para garantir } \\
\text { uma terapia } \\
\text { intravenosa segura em } \\
\text { longo tempo para } \\
\text { neonatos por meio do } \\
\text { CCIP. }\end{array}$ & $\begin{array}{l}\text { Para a manutenção do cateter er não } \\
\text { complicações pelo dispositivo, os } \\
\text { profissionais requerem capacitação e } \\
\text { habilitação profissional para a tomada de } \\
\text { decisão, a inserção, a manutenção e a } \\
\text { retirada, visando a redução de eventos } \\
\text { adversos e a manutenção do bem-estar do } \\
\text { neonato. }\end{array}$ \\
\hline 6 & $\begin{array}{c}\text { Acta } \\
\text { Paul } \\
\text { Enferm }\end{array}$ & $\begin{array}{l}\text { LILA } \\
\text { CS }\end{array}$ & $\begin{array}{c}\text { Silva et } \\
\text { al., } 2019 .\end{array}$ & $\begin{array}{l}\text { Bundle para manuseio } \\
\text { do cateter central de } \\
\text { inserção periférica em } \\
\text { neonatos. }\end{array}$ & $\begin{array}{c}\text { Estudo } \\
\text { qualitativo. }\end{array}$ & 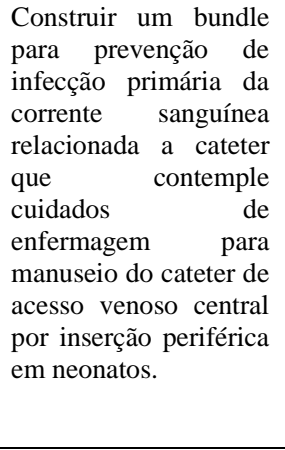 & $\begin{array}{l}\text { O Cateter de Acesso Venoso Central por } \\
\text { Inserção Periférica é amplamente utilizado } \\
\text { em neonatos, devido vantagens como o } \\
\text { tempo de permanência prolongado, redução } \\
\text { do número de punção, menor risco de flebite, } \\
\text { infiltração e extravasamento. Uma das } \\
\text { estratégias para minimizar as IPCS-RC e } \\
\text { garantir a segurança do paciente é a } \\
\text { sistematização dos cuidados, uma vez que } \\
\text { reduz a variabilidade na assistência. O } \\
\text { bundle consiste em um conjunto de cuidados } \\
\text { específicos, quando utilizados juntos com } \\
\text { ferem melhorias substanciais na assistência à } \\
\text { saúde. }\end{array}$ \\
\hline 7 & $\begin{array}{l}\text { J Res } \\
\text { Funda } \\
\text { m Care } \\
\text { Online }\end{array}$ & $\begin{array}{l}\text { LILA } \\
\text { CS }\end{array}$ & $\begin{array}{l}\text { Rangel et } \\
\text { al., } 2019 .\end{array}$ & $\begin{array}{lr}\text { Práticas de } & \text { Inserção, } \\
\text { Manutenção } & \text { e } \\
\text { Remoça do Cateter } \\
\text { Central de } & \text { Inserção } \\
\text { Periférica } & \text { em } \\
\text { Neonatos. } & \end{array}$ & $\begin{array}{l}\text { Estudo } \\
\text { quantitativo } \\
\text { do tipo } \\
\text { correlacional } \\
\text { retrospectivo. }\end{array}$ & $\begin{array}{l}\text { Avaliar as práticas de } \\
\text { enfermagem na na } \\
\text { inserção, manutenção } \\
\text { e remoção do PICC } \\
\text { em neonatos. }\end{array}$ & $\begin{array}{l}\text { A vigilância rigorosa na utilização do PICC } \\
\text { é imprescindível para segurança do paciente, } \\
\text { que é a dimensão da qualidade mais crítica e } \\
\text { decisiva, visto que corresponde à redução ao } \\
\text { mínimo aceitável do risco de dano } \\
\text { desnecessário associado ao cuidado de } \\
\text { saúde. Além do embasamento teórico e das } \\
\text { habilidades técnica que suportem a } \\
\text { promoçãa de resultados assistenciais efetivos } \\
\text { na inserção e manutenção do PICC, é } \\
\text { requerido o amparo legal. Neste sentido, o } \\
\text { Conselho Federal de Enfermagem no Brasil } \\
\text { por meio da Resolução no } 258 / 2001 \text { define a } \\
\text { inserção e manutenção do PICC como } \\
\text { competência técnica e legal para enfermeiro } \\
\text { devidamente qualificado e/ou capacitado } \\
\text { profissionalmente para tal procedimento. }\end{array}$ \\
\hline 8 & $\begin{array}{l}\text { Rev } \\
\text { Rene. }\end{array}$ & $\begin{array}{l}\text { BDE } \\
\text { NF }\end{array}$ & $\begin{array}{l}\text { Lanza et } \\
\text { al., } 2019 .\end{array}$ & $\begin{array}{lr}\text { Medidas } & \text { preventivas } \\
\text { de } & \text { infecção } \\
\text { relacionada ao cateter } \\
\text { venoso periférico: } \\
\text { adesão em terapia } \\
\text { intensiva. }\end{array}$ & $\begin{array}{c}\text { Estudo } \\
\text { transversal. }\end{array}$ & $\begin{array}{l}\text { Analisar a adesão dos } \\
\text { profissionais de en- } \\
\text { fermagem às medidas } \\
\text { de prevenção de } \\
\text { infecção por cateter } \\
\text { venoso periférico. }\end{array}$ & $\begin{array}{l}\text { A manipulação adequada dos cateteres } \\
\text { diminui o risco de infeção. Logo, } \\
\text { recomenda-se a utilização de protocolos } \\
\text { institucionais validados e a aplicação } \\
\text { conjunta de medidas preventivas "Bundles", } \\
\text { visando reduzir as infecções primárias de } \\
\text { corrente sanguínea. O bundle relacionado ao } \\
\text { cateter venoso periférico de medidas da } \\
\text { Agência Nacional de Vigilância Sanitária } \\
\text { compreende cinco componentes: 1- } \\
\text { higienização das mãos; 2- precaução de } \\
\text { barreira máxima; 3- preparo da pele com } \\
\text { gluconato de clorexidine; 4- seleçãa de sítio } \\
\text { de inserção; e } 5 \text { - revisão diária da } \\
\text { necessidade de per- manência do cateter. }\end{array}$ \\
\hline 9 & $\begin{array}{l}\text { Rev } \\
\text { Rene. }\end{array}$ & $\begin{array}{l}\text { BDE } \\
\mathrm{NF}\end{array}$ & $\begin{array}{l}\text { Baggio, } \\
\text { Cheffer, } \\
\text { Luz, } \\
\text { Sanches, } \\
\text { \& Berres, } \\
2019 .\end{array}$ & $\begin{array}{l}\text { Utilização do cateter } \\
\text { central de inserção } \\
\text { periférica } \\
\text { neonatos: análise da } \\
\text { indicação à remoção. }\end{array}$ & $\begin{array}{c}\text { Estudo } \\
\text { retrospectivo, } \\
\text { documental. }\end{array}$ & $\begin{array}{l}\text { Analisar a utilização } \\
\text { do cateter central de } \\
\text { inserção periférica em } \\
\text { neonatos. }\end{array}$ & $\begin{array}{l}\text { O cateter central de inserção periférica é um } \\
\text { dispositivo de acesso vascular, inserido em } \\
\text { uma extremidade, como veia basílica ou } \\
\text { cefálica, e avançado até que a ponta esteja } \\
\text { posicionada no terço médio da veia cava } \\
\text { superior ou inferior. Uma das indicações é a } \\
\text { terapia intravenosa de longa duração, } \\
\text { superior a seis dias, utilizada em } \\
\text { Neonatologia e Pediatria. }\end{array}$ \\
\hline
\end{tabular}




\begin{tabular}{|c|c|c|c|c|c|c|c|}
\hline $\begin{array}{l}1 \\
0\end{array}$ & $\begin{array}{c}\text { Rev } \\
\text { Enferm } \\
\text { UERJ. }\end{array}$ & $\begin{array}{l}\text { BDE } \\
\text { NF }\end{array}$ & $\begin{array}{l}\text { Sá Neto } \\
\text { et al., } \\
2018 .\end{array}$ & $\begin{array}{ll}\text { Conhecimento de } \\
\text { enfermeiros acerca do } \\
\text { cateter central de } \\
\text { inserção periférica: } \\
\text { realidade local e } \\
\text { desafios globais. }\end{array}$ & $\begin{array}{c}\text { Estudo } \\
\text { descritivo } \\
\text { seccional. }\end{array}$ & 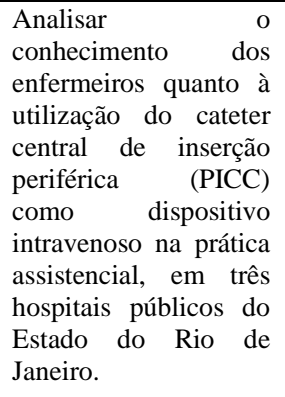 & $\begin{array}{l}\text { Para que haja sucesso na prática clínica com } \\
\text { o PICC alguns fatores devem ser } \\
\text { considerados, como a habilidade e } \\
\text { capacitação técnica do profissional } \\
\text { enfermeiro, conhecimento sobre o cateter, } \\
\text { indicação, contraindicação, eleiçãao do vaso } \\
\text { que será puncionado, técnica de inserção, } \\
\text { complicaçães, bem como, cuidado } \\
\text { específicos para inserção, manutenção e } \\
\text { remoção ao final da indicação terapêutica. }\end{array}$ \\
\hline $\begin{array}{l}1 \\
1\end{array}$ & $\begin{array}{l}\text { Rev } \\
\text { Enferm } \\
\text { UERJ. }\end{array}$ & $\begin{array}{c}\text { BDE } \\
\text { NF }\end{array}$ & $\begin{array}{c}\text { Borghesa } \\
\text { n et al., } \\
2017 \text {. }\end{array}$ & $\begin{array}{lr}\text { Cateter venoso central } \\
\text { de inserção periférica: } \\
\text { práticas da equipe de } \\
\text { enfermagem } \\
\text { atenção } & \text { na } \\
\text { neonatal. } & \\
\text { intensiva } \\
\end{array}$ & $\begin{array}{l}\text { Estudo obser- } \\
\text { vacional, des } \\
\text { - critivo } \\
\text { quantitativo. }\end{array}$ & $\begin{array}{l}\text { Traçar o perfil de } \\
\text { utilização do cateter } \\
\text { venoso central de } \\
\text { inserção periférica } \\
\text { (PICC) na realidade } \\
\text { assistencial da unidade } \\
\text { de terapia intensiva } \\
\text { neonatal (UTIN). }\end{array}$ & $\begin{array}{l}\text { A manutenção do PICC exige cuidados. } \\
\text { Recomenda-se que em pacientes neonatos, a } \\
\text { troca do curativo seja realizada somente se } \\
\text { estiver descolando, apresentarem sujidade, } \\
\text { umidade ou sangramento, não havendo um } \\
\text { prazo determinado, uma vez que em } \\
\text { pediatria o risco de deslocamento do PICC é } \\
\text { maior que o benefício da troca. Vale } \\
\text { evidenciar que a confeção do curativo é } \\
\text { atividade privativa do enfermeiro. }\end{array}$ \\
\hline $\begin{array}{l}1 \\
2\end{array}$ & $\begin{array}{l}\text { Rev } \\
\text { Enferm } \\
\text { UFPE } \\
\text { On } \\
\text { line. }\end{array}$ & $\begin{array}{l}\text { BDE } \\
\text { NF }\end{array}$ & $\begin{array}{l}\text { Barbosa } \\
\text { et al., } \\
2017 .\end{array}$ & $\begin{array}{l}\text { Saberes da equipe de } \\
\text { enfermagem sobre } \\
\text { cuidados com cateter } \\
\text { venoso central. }\end{array}$ & $\begin{array}{l}\text { Estudo } \\
\text { quantitativo, } \\
\text { descritivo, } \\
\text { exploratório, } \\
\text { transversal. }\end{array}$ & $\begin{array}{l}\text { Avaliar } \quad \text { o } \\
\text { conhecimento da } \\
\text { equipe de enfermagem } \\
\text { sobre as boas práticas } \\
\text { de manutenção e } \\
\text { curativo de cateter } \\
\text { venoso central (CVC) } \\
\text { em conformidade com } \\
\text { o protocolo } \\
\text { institucional. }\end{array}$ & $\begin{array}{l}\text { O estudo evidenciou o desconhecimento dos } \\
\text { profissionais de enfermagem em relação às } \\
\text { práticas preconizadas pelo protocolo } \\
\text { institucional. Embora o manuseio do cateter } \\
\text { venoso central seja uma prática rotineira da } \\
\text { enfermagem e, aparentemente, simples, } \\
\text { exige cuidados específicos e observação } \\
\text { rigorosa das medidas preconizadas a fim de } \\
\text { melhorar a segurança dos pacientes e a } \\
\text { qualidade da assistência prestada. }\end{array}$ \\
\hline $\begin{array}{l}1 \\
3\end{array}$ & $\begin{array}{l}\text { Rev } \\
\text { Esc } \\
\text { Enferm } \\
\text { USP. }\end{array}$ & $\begin{array}{c}\text { LILA } \\
\text { CS }\end{array}$ & $\begin{array}{c}\text { Gomes, } \\
\& \\
\text { Nascime } \\
\text { nto, } \\
2013 .\end{array}$ & $\begin{array}{l}\text { O processo do } \\
\text { cateterismo venoso } \\
\text { central em Unidade de } \\
\text { Terapia Intensiva } \\
\text { Neonatal e Pediátrica. }\end{array}$ & $\begin{array}{c}\text { Estudo } \\
\text { descritivo, } \\
\text { longitudinal e } \\
\text { quantitativo. }\end{array}$ & $\begin{array}{lr}\text { Analisar e discutir o } \\
\text { processo } & \text { do } \\
\text { cateterismo venoso } \\
\text { central nas } & \text { Unidades } \\
\text { de Terapia Intensiva } \\
\text { Neonatal e Pediátrica. }\end{array}$ & $\begin{array}{l}\text { A análise crítica do processo do cateterismo } \\
\text { venoso central possibilitou rever a prática } \\
\text { assistencial para estabelecer o } \\
\text { aprimoramento da assistência prestada à } \\
\text { clientela neonatal e pediátrica internadas nas } \\
\text { Unidades de Terapia Intensiva. Em relação à } \\
\text { terapia intravenosa, indicação dos } \\
\text { dispositivos intravasculares centrais, relação } \\
\text { custo-benefício na realização dos cuidados e } \\
\text { eleição de recursos tecnológicos e } \\
\text { desenvolvimento de novas pesquisas na área, } \\
\text { a fim de assegurar a qualidade do cuidado, } \\
\text { garantindo a segurança dessa clientela. }\end{array}$ \\
\hline $\begin{array}{l}1 \\
4\end{array}$ & $\begin{array}{l}\text { Rev } \\
\text { Esc } \\
\text { Enferm } \\
\text { USP. }\end{array}$ & $\begin{array}{l}\text { BDE } \\
\text { NF }\end{array}$ & $\begin{array}{l}\text { Duarte, } \\
\text { Pimenta, } \\
\text { Silva, \& } \\
\text { Paula, } \\
\text { 2013. }\end{array}$ & $\begin{array}{l}\text { Fatores associados à } \\
\text { infecção pelo uso do } \\
\text { cateter central de } \\
\text { inserção periférica em } \\
\text { Unidade de Terapia } \\
\text { Intensiva Neonatal. }\end{array}$ & $\begin{array}{c}\text { Estudo } \\
\text { epidemiológi- } \\
\text { co, } \\
\text { longitudinal e } \\
\text { analítico. }\end{array}$ & $\begin{array}{l}\text { Analisar os fatores } \\
\text { associados à infecção } \\
\text { pelo uso do cateter } \\
\text { central de inserção } \\
\text { periférica em recém- } \\
\text { nascidos internados } \\
\text { em Unidade de } \\
\text { Terapia Intensiva. }\end{array}$ & $\begin{array}{l}\text { A indicação de uso do PICC é determinada } \\
\text { pela equipe de saúde que assiste a criança e } \\
\text { usualmente se destina a administração de } \\
\text { antibióticos, nutrição parenteral ou substi - } \\
\text { tuição do cateter venoso umbilical. O } \\
\text { procedimento de inserção é realizado por } \\
\text { enfermeiros capacitados, sob a orientação de } \\
\text { um protocolo institucional baseado nas } \\
\text { diretrizes da Sociedade Brasileira de } \\
\text { Enfermeiros de Terapia Intravenosa. }\end{array}$ \\
\hline $\begin{array}{l}1 \\
5\end{array}$ & $\begin{array}{l}\text { Rev } \\
\text { Enferm } \\
\text { UFPE } \\
\text { Online. }\end{array}$ & $\begin{array}{l}\text { BDE } \\
\text { NF }\end{array}$ & $\begin{array}{c}\text { Mingoran } \\
\text { ce, } \\
\text { Johann, } \\
\text { Lazzari, } \\
\text { Pedrolo, } \\
\& \\
\text { Danski, } \\
2015 .\end{array}$ & $\begin{array}{l}\text { Relações significativas } \\
\text { acerca do cateter } \\
\text { central de inserção } \\
\text { Periférica. }\end{array}$ & $\begin{array}{c}\text { Estudo } \\
\text { Exploratório, } \\
\text { descritivo e } \\
\text { documental } \\
\text { retrospectivo } \\
\text { quantitativo. }\end{array}$ & $\begin{array}{l}\text { Relacionar } r \text { as } \\
\text { características sócio - } \\
\text { demográficas } \\
\text { clínicas de neonatos } \\
\text { em uso do cateter } \\
\text { central de inserção } \\
\text { periférica ràs } \\
\text { complicações associa- } \\
\text { das. }\end{array}$ & $\begin{array}{l}\text { Identifica-se relação significativa entre } \\
\text { variáveis clínicas e a ocorrência de } \\
\text { complicações. Destaca-se que os fatores } \\
\text { como apgar, parkin, peso ao nascer, apesar } \\
\text { de apresentarem relação, não podem ser } \\
\text { modificados pela prática de enfermagem. } \\
\text { Entretanto o número de tentativas de punção } \\
\text { e a realização do flush são procedimentos } \\
\text { que podem ser modificados a fim de reduzir } \\
\text { o risco a eles associados. }\end{array}$ \\
\hline
\end{tabular}




\begin{tabular}{|c|c|c|c|c|c|c|c|}
\hline $\begin{array}{l}1 \\
6\end{array}$ & $\begin{array}{l}\text { Rev } \\
\text { Eletr } \\
\text { Enf } \\
\text { [Intern } \\
\text { et]. }\end{array}$ & $\begin{array}{l}\text { BDE } \\
\text { NF }\end{array}$ & $\begin{array}{l}\text { Swerts, } \\
\text { Felipe, } \\
\text { Rocha, \& } \\
\text { Andrade, } \\
2013 .\end{array}$ & $\begin{array}{ll}\text { Cuidados } & \text { de } \\
\text { enfermagem frente às } \\
\text { complicações } & \text { do } \\
\text { cateter central de } & \text { de } \\
\text { inserção periférica } & \text { em } \\
\text { neonatos. }\end{array}$ & $\begin{array}{c}\text { Estudo } \\
\text { descritivo } \\
\text { observacional } \\
\text { quantitativo. }\end{array}$ & $\begin{array}{l}\text { Avaliar os cuidados de } \\
\text { enfermagem frente às } \\
\text { complicações relacio - } \\
\text { nadas ao cateter } \\
\text { central de inserção } \\
\text { periférica (CCIP) em } \\
\text { neonatos. }\end{array}$ & $\begin{array}{l}\text { O CCIP é um avanço nas Unidades de } \\
\text { Terapia Intensiva Neonatal, no entanto é } \\
\text { necessário que a equipe de enfermagem } \\
\text { esteja preparada e treinada para prestar } \\
\text { assistência de qualidade após sua inserção. } \\
\text { Para que a equipe de enfermagem obtenha o } \\
\text { sucesso com a implantação do cateter, esta } \\
\text { deve ter conhecimento sobre os riscos } \\
\text { envolvidos no seu uso. As complicaçães } \\
\text { durante a sua inserção, manutenção e } \\
\text { remoção, são os principais motivos para a } \\
\text { retirada prematura do cateter. Os cuidados de } \\
\text { enfermagem são fatores essenciais na } \\
\text { manutenção do CCIP. A identificação das } \\
\text { possíveis complicações relacionadas ao seu } \\
\text { uso torna-se uma necessidade para esses } \\
\text { profissionais que atuam diretamente na sua } \\
\text { manipulação. }\end{array}$ \\
\hline $\begin{array}{l}1 \\
7\end{array}$ & $\begin{array}{c}\text { Rev } \\
\text { Bras } \\
\text { Enferm }\end{array}$ & $\begin{array}{l}\text { LILA } \\
\text { CS }\end{array}$ & $\begin{array}{l}\text { Belo, } \\
\text { Silva, } \\
\text { Nogueira } \\
\quad, \\
\text { Mizoguti, } \\
\quad \& \\
\text { Ventura, } \\
2012 .\end{array}$ & $\begin{array}{lr}\text { Conhecimento } & \text { de } \\
\text { enfermeiros } & \text { de } \\
\text { Neonatologia } & \text { acerca } \\
\text { do Cateter } & \text { Venoso } \\
\text { Central de } & \text { Inserção } \\
\text { Periférica. } & \end{array}$ & $\begin{array}{c}\text { Estudo } \\
\text { descritivo, } \\
\text { transversal, } \\
\text { quantitativo. }\end{array}$ & $\begin{array}{lr}\text { Analisar } & o \\
\text { conhecimento e a } & \text { ática dos } \\
\text { prática } & \text { enfermeiros acerca da } \\
\text { utilização do PICC em } \\
\text { recém-nascidos. }\end{array}$ & $\begin{array}{l}\text { O Cateter Central de Inserção Periférica } \\
\text { (PICC) vem sendo utilizado como alternativa } \\
\text { de acesso venoso estável e eficaz para } \\
\text { neonatos criticamente enfermos. Trata-se de } \\
\text { um cateter longo e flexível, inserido através } \\
\text { de uma veia periférica que, por meio de uma } \\
\text { agulha introdutora, progride até o terço distal } \\
\text { da veia cava superior ou veia cava inferior, } \\
\text { adquirindo dessa forma propriedades de } \\
\text { acesso venoso central. }\end{array}$ \\
\hline $\begin{array}{l}1 \\
8\end{array}$ & $\begin{array}{c}\text { Rev } \\
\text { Bras } \\
\text { Enferm }\end{array}$ & $\begin{array}{l}\text { LILA } \\
\text { CS }\end{array}$ & $\begin{array}{l}\text { Dórea, } \\
\text { Castro, } \\
\text { Costa, } \\
\text { Kimura, } \\
\text { \& Santos, } \\
2011 .\end{array}$ & $\begin{array}{l}\text { Práticas de manejo do } \\
\text { Cateter Central de } \\
\text { Inserção Periférica em } \\
\text { uma unidade neonatal. }\end{array}$ & $\begin{array}{c}\text { Estudo } \\
\text { quantitativo } \\
\text { descritivo } \\
\text { exploratório. }\end{array}$ & $\begin{array}{l}\text { Descrever o manejo } \\
\text { dos PICCs } \\
\text { em instalados } \\
\text { internados em neonatos } \\
\text { UCIN de um Hospital } \\
\text { privado. }\end{array}$ & $\begin{array}{l}\text { O papel do enfermeiro é de fundamental } \\
\text { importância na realização dos cuidados do } \\
\text { PICC. A elaboração de um impresso de fácil } \\
\text { utilização pode ser uma forma de solucionar } \\
\text { os problemas oriundos da falta ou } \\
\text { inadequado registro de qualquer } \\
\text { procedimento realizado com o CCIP. }\end{array}$ \\
\hline $\begin{array}{l}1 \\
9\end{array}$ & $\begin{array}{l}\text { HU } \\
\text { Revista } \\
\text { Juiz de } \\
\text { Fora. }\end{array}$ & $\begin{array}{l}\text { BDE } \\
\text { NF }\end{array}$ & $\begin{array}{l}\text { Motta, } \\
\text { Fialho, } \\
\text { Dias, \& } \\
\text { Nascim } \\
\text { nto, } \\
2011 .\end{array}$ & $\begin{array}{l}\text { Cateter central de } \\
\text { inserção periférica: o } \\
\text { papel da enfermagem } \\
\text { na sua utilização em } \\
\text { neonatologia. }\end{array}$ & $\begin{array}{c}\text { Estudo } \\
\text { documental. }\end{array}$ & $\begin{array}{l}\text { Verificar a utilização } \\
\text { PICC em uma UTI } \\
\text { neonatal, caracterizar } \\
\text { o perfil do recém- } \\
\text { nascido submetido ao } \\
\text { PICC, identificar as } \\
\text { indicações do uso e } \\
\text { apresentar os fatores } \\
\text { que levaram à retirada } \\
\text { do PICC. }\end{array}$ & $\begin{array}{l}\text { Evidencia-se que é frequente a necessidade } \\
\text { de acesso venoso prolongado para o } \\
\text { tratamento de neonatos em cuidado } \\
\text { intensivo. Por conta do curto tempo de } \\
\text { permanência dos cateteres venosos } \\
\text { periféricos, os cateteres venosos centrais têm } \\
\text { sido usados cada vez mais em UTIs } \\
\text { neonatais. Os PICC têm sido utilizados no } \\
\text { tratamento de recém-nascidos há quase três } \\
\text { décadas, particularmente nos recém-nascidos } \\
\text { pré-termos que necessitam de acesso venoso } \\
\text { prolongado para receber nutrição. Suas } \\
\text { vantagens estão relacionadas à possibilidade } \\
\text { de suporte nutricional via parenteral, à } \\
\text { administração mais segura de líquidos, à } \\
\text { possibilidade de monitorização } \\
\text { hemodinâmica e à maior facilidade em } \\
\text { mantê-los, evitando o estresse e o } \\
\text { desconforto de repetidas punções. }\end{array}$ \\
\hline $\begin{array}{l}2 \\
0\end{array}$ & $\begin{array}{l}\text { Rev. } \\
\text { Adm. } \\
\text { Saúde. }\end{array}$ & $\begin{array}{l}\text { SCIE } \\
\text { LO }\end{array}$ & $\begin{array}{l}\text { Sousa, } \\
\text { Pereira, } \\
\text { Rezende, } \\
\& \text { Laura, } \\
2018 .\end{array}$ & $\begin{array}{l}\text { Avaliação dos } \\
\text { cuidados } \\
\text { enfermagem com o } \\
\text { cateter venoso central } \\
\text { em uma unidade de } \\
\text { terapia intensiva } \\
\text { adulto e pediátrica. }\end{array}$ & $\begin{array}{c}\text { Estudo de } \\
\text { auditoria } \\
\text { clínica. }\end{array}$ & $\begin{array}{l}\text { Avaliar os cuidados de } \\
\text { enfermagem relaciona- } \\
\text { dos ao CVC nas } \\
\text { unidades de terapia } \\
\text { intensiva pediátrica, de } \\
\text { um hospital público de } \\
\text { alta complexidade de } \\
\text { Minas Gerais. }\end{array}$ & $\begin{array}{l}\text { Os cuidados com os CVC são de inteira } \\
\text { responsabilidade dos enfermeiros, que } \\
\text { exercem papel fundamental na manutenção e } \\
\text { na retirada do cateter. Pode-se citar como } \\
\text { cuidados de enfermagem a higienização das } \\
\text { mãos, a avaliação do sítio do cateter, a } \\
\text { desinfecção dos conectores do CVC, preparo } \\
\text { e administração de medicamento se a troca } \\
\text { do sistema de infusão. }\end{array}$ \\
\hline $\begin{array}{l}2 \\
1\end{array}$ & $\begin{array}{l}\text { Rev } \\
\text { Pre } \\
\text { Infec e } \\
\text { Saúde. }\end{array}$ & $\begin{array}{l}\text { SCIE } \\
\text { LO }\end{array}$ & $\begin{array}{c}\text { Cavalcan } \\
\text { te } \text { et al., } \\
2015 \text {. }\end{array}$ & $\begin{array}{lr}\text { Cuidados } & \text { de } \\
\text { enfermagem } & \text { na } \\
\text { manutenção do cateter } \\
\text { central de inserção } \\
\text { periférica } \\
\text { neonatos. }\end{array}$ & $\begin{array}{c}\text { Estudo } \\
\text { qualitativo. }\end{array}$ & $\begin{array}{l}\text { Analisar os cuidados } \\
\text { de enfermagem na } \\
\text { manutenção do cateter } \\
\text { central de inserção } \\
\text { periférica em neonatos } \\
\text { nos periódicos } \\
\text { científicos. }\end{array}$ & $\begin{array}{l}\text { Diante essa prática, sabe-se que o grande } \\
\text { desafio é evitar infecções, pois existem } \\
\text { fatores de risco associados ao cateter venoso } \\
\text { central que podem estar relacionados a } \\
\text { doenças pré-existentes e a fatores clínicos } \\
\text { como admissão em UTIN, uso de ventilação } \\
\text { mecânica e monitoramento hemodinâmico } \\
\text { invasivo. }\end{array}$ \\
\hline
\end{tabular}




\begin{tabular}{|c|c|c|c|c|c|c|c|}
\hline $\begin{array}{l}2 \\
2\end{array}$ & $\begin{array}{l}\text { R Pesq } \\
\text { Cuid } \\
\text { Fundm } \\
\text { Online. }\end{array}$ & $\begin{array}{l}\text { SCIE } \\
\text { LO }\end{array}$ & $\begin{array}{c}\text { Barbosa, } \\
2011 .\end{array}$ & $\begin{array}{l}\text { A importância do } \\
\text { enfermeiro no } \\
\text { manuseio do PICC na } \\
\text { unidade de terapia } \\
\text { intensiva neonatal. }\end{array}$ & $\begin{array}{c}\text { Estudo } \\
\text { exploratório e } \\
\text { descritivo, } \\
\text { com } \\
\text { qualitativo. }\end{array}$ & $\begin{array}{lr}\text { Identificar } & \text { as } \\
\text { dificuldades } & \\
\text { encontradas } & \text { pelo } \\
\text { enfermeiro } & \text { na } \\
\text { manutenção } & \text { desse } \\
\text { cateter, de } & \text { modo a } \\
\text { contribuir } & \text { para } \\
\text { melhoria da assistência } \\
\text { prestada ao recém- } \\
\text { nascido. }\end{array}$ & $\begin{array}{l}\text { A atuação do enfermeiro torna-se } \\
\text { indispensável, e que o manuseio deste } \\
\text { dispositivo requer conhecimento, destreza e } \\
\text { habilidade por parte dos enfermeiros e } \\
\text { membros da equipe de saúde. O sucesso da } \\
\text { utilização do PICC seja alcançado é } \\
\text { necessário que os profissionais de } \\
\text { enfermagem busquem o conhecimento } \\
\text { técnico e cientifico por meio de treinamentos } \\
\text { e habilitações, para evitar complicações e } \\
\text { saber intervir diante de problemas já } \\
\text { instalados. }\end{array}$ \\
\hline $\begin{array}{l}2 \\
3\end{array}$ & $\begin{array}{l}\text { Revista } \\
\text { Pró- } \\
\text { Univer } \\
\text { SUS }\end{array}$ & $\begin{array}{l}\text { SCIE } \\
\text { LO }\end{array}$ & $\begin{array}{l}\text { Ribeiro } \\
\text { et al., } \\
2018 .\end{array}$ & $\begin{array}{l}\text { Cateter venoso central } \\
\text { na UTI pediátrica: o } \\
\text { enfermeiro intensivista } \\
\text { na prevenção e } \\
\text { controle das infecções } \\
\text { hospitalares. }\end{array}$ & $\begin{array}{c}\text { Estudo } \\
\text { qualitativo de } \\
\text { caráter } \\
\text { descritivo. }\end{array}$ & $\begin{array}{l}\text { Identificar as possíveis } \\
\text { estratégias utilizadas } \\
\text { pelo enfermeiro na } \\
\text { prevenção e controle } \\
\text { das infecções } \\
\text { relacionadas ao cateter } \\
\text { vascular central na } \\
\text { UTI pediátrica. }\end{array}$ & $\begin{array}{l}\text { A manipulação de um CVC após a sua } \\
\text { inserção até a sua remoção é de } \\
\text { responsabilidade do enfermeiro e de sua } \\
\text { equipe. Sendo assim, destaca-se a } \\
\text { necessidade de conhecimento, habilidades e } \\
\text { treinamento do enfermeiro e equipe para o } \\
\text { manejo seguro dos dispositivos } \\
\text { intravasculares, principalmente o CVC. } \\
\text { Especificamente, uma assistência de } \\
\text { enfermagem prestada ao paciente em uso de } \\
\text { CVC pode levar a complicações, como as } \\
\text { infecções de corrente sanguínea, o que } \\
\text { aumenta o período de internação, a } \\
\text { morbimortalidade e os custos da } \\
\text { hospitalização. }\end{array}$ \\
\hline $\begin{array}{l}2 \\
4\end{array}$ & $\begin{array}{l}\text { Revista } \\
\text { Enferm } \\
\text { agem } \\
\text { em } \\
\text { Evidên } \\
\text { cia. }\end{array}$ & $\begin{array}{l}\text { SCIE } \\
\text { LO }\end{array}$ & $\begin{array}{l}\text { Borges, } \\
\text { Souza, \& } \\
\text { Spolidoro } \\
\text {,2018. }\end{array}$ & $\begin{array}{l}\text { Atuação do enfermeiro } \\
\text { frente ao risco de } \\
\text { infeção com cateter } \\
\text { venoso central na } \\
\text { unidade de terapia } \\
\text { intensiva. }\end{array}$ & $\begin{array}{c}\text { Estudo } \\
\text { qualitativo. }\end{array}$ & $\begin{array}{l}\text { Identificar na literatura } \\
\text { quais as medidas } \\
\text { preventivas e de } \\
\text { controle de infecção } \\
\text { relacionada ao uso de } \\
\text { cateter venoso central } \\
\text { em UTI, e, identificar } \\
\text { as causas, os tipos e os } \\
\text { fatores de risco para } \\
\text { essa infecção. }\end{array}$ & $\begin{array}{l}\text { Para prevenir estas infecções a equipe de } \\
\text { enfermagem que atua nas UTIs devem } \\
\text { adotar as seguintes medidas: Higienização } \\
\text { das mãos antes da manipulação do cateter; } \\
\text { Realizar degermação adequada no preparo } \\
\text { da pele para punção de CVC; Realização de } \\
\text { curativo, preferencialmente transparente } \\
\text { estéril, para cobertura do dispositivo com sua } \\
\text { troca sempre que sujo, úmido ou solto; } \\
\text { Revisão diária da necessidade de uso do } \\
\text { dispositivo com sua remoção imediata } \\
\text { quando não mais essencial; e Educação da } \\
\text { equipe. }\end{array}$ \\
\hline $\begin{array}{l}2 \\
5\end{array}$ & $\begin{array}{l}\text { Resear } \\
\text { ch, } \\
\text { Society } \\
\text { and } \\
\text { Develo } \\
\text { pment. }\end{array}$ & $\begin{array}{l}\text { SCIE } \\
\text { LO }\end{array}$ & $\begin{array}{l}\text { Ribeiro } \\
\text { et al., } \\
2020 .\end{array}$ & $\begin{array}{lr}\text { Prevenção de infecção } \\
\text { relacionada à cateter } \\
\text { venoso } & \text { central: } \\
\text { cuidados } & \mathrm{e} \\
\text { conhecimento } & \text { da } \\
\text { equipe de enfermagem }\end{array}$ & $\begin{array}{c}\text { Estudo } \\
\text { qualitativo. }\end{array}$ & $\begin{array}{ll}\text { Identificar } & \text { os } \\
\text { principais cuidados de } & \text { na } \\
\text { enfermagem } & \text { na } \\
\text { prevenção de infecção } \\
\text { relacionada à cateter } \\
\text { venoso central. }\end{array}$ & $\begin{array}{l}\text { A inserção de um cateter venoso central } \\
\text { (CVC) é considerado um procedimento } \\
\text { invasivo, deve-se considerar as indicações e } \\
\text { contraindicações, realizando o procedimento } \\
\text { prioritariamente quando houver necessidade, } \\
\text { uma vez que, sua utilização está relacionada } \\
\text { com complicações como as tromboses, } \\
\text { hidrotórax, hemotórax, pneumotórax, } \\
\text { fistulas, aneurismae infecções }\end{array}$ \\
\hline $\begin{array}{l}2 \\
6\end{array}$ & $\begin{array}{l}\text { Portug } \\
\text { uese } \\
\text { ReOnF } \\
\text { acema. }\end{array}$ & $\begin{array}{l}\text { SCIE } \\
\text { LO }\end{array}$ & $\begin{array}{l}\text { Vera, } \\
\text { Sousa, \& } \\
\text { Araújo, } \\
2015 .\end{array}$ & $\begin{array}{l}\text { A atuação do } \\
\text { enfermeiro na prática } \\
\text { de inserção e } \\
\text { manutenção do PICC. }\end{array}$ & $\begin{array}{c}\text { Estudo } \\
\text { qualitativo. }\end{array}$ & $\begin{array}{l}\text { Analisar sobre a } \\
\text { inserção e manutenção } \\
\text { do PICC em neonatos. }\end{array}$ & $\begin{array}{l}\text { Evidencia-se o papel extremamente } \\
\text { importante da equipe de enfermagem no que } \\
\text { se refere as práticas e intervenções com } \\
\text { conhecimento técnico-científico, durante à } \\
\text { implantação e manutenção do dispositivo } \\
\text { PICC em neonatos internados na UTIN. } \\
\text { Portanto cabe ao enfermeiro aprofundar-se } \\
\text { neste mundo fascinante que é a passagem do } \\
\text { PICC, pois na medida que amplia seus } \\
\text { conhecimento á este procedimento, viabiliza } \\
\text { as condições positivas e o desenvolvimento } \\
\text { do paciente prematuro. }\end{array}$ \\
\hline $\begin{array}{l}2 \\
7\end{array}$ & $\begin{array}{l}\text { Revista } \\
\text { da } \\
\text { Univer } \\
\text { sidade } \\
\text { Vale } \\
\text { do Rio } \\
\text { Verde, } \\
\text { Três } \\
\text { Coraçõ } \\
\text { es. }\end{array}$ & $\begin{array}{l}\text { SCIE } \\
\text { LO }\end{array}$ & $\begin{array}{l}\text { Sirqueira, } \\
\text { \& Souza, } \\
2017 .\end{array}$ & $\begin{array}{l}\text { Cuidados de } \\
\text { enfermagem na } \\
\text { manutenção do cateter } \\
\text { Central de inserção } \\
\text { periférica no recém - } \\
\text { nascido. }\end{array}$ & $\begin{array}{c}\text { Estudo } \\
\text { qualitativo, } \\
\text { exploratório } \\
\text { descritivo. }\end{array}$ & $\begin{array}{l}\text { Analisar os cuidados } \\
\text { de enfermagem na } \\
\text { manutenção Cateter } \\
\text { Central de Inserção } \\
\text { Periférica no recém- } \\
\text { nascido. }\end{array}$ & $\begin{array}{l}\text { Exige-se conhecimentos técnico-científicos } \\
\text { específicos para a passagem do PICC, pois } \\
\text { este é um procedimento de alta } \\
\text { complexidade técnica. De acordo com a } \\
\text { Intravenous Nurses Society (INS) - Brasil, } \\
\text { cabe privativamente aos enfermeiros e } \\
\text { médicos a realização de tal procedimento, } \\
\text { desde que tenham feito a capacitação através } \\
\text { de curso e treinamento que inclua os } \\
\text { conteúdos teórico-práticos relativos à } \\
\text { inserção, manutenção e retirada do cateter, } \\
\text { indicações e contra indicações da utilização } \\
\text { do dispositivo e métodos de verificação da } \\
\text { inserção. }\end{array}$ \\
\hline
\end{tabular}




\begin{tabular}{|c|c|c|c|c|c|c|c|}
\hline $\begin{array}{l}2 \\
8\end{array}$ & $\begin{array}{c}\text { Saúde } \\
\& \\
\text { Ciência } \\
\text { em } \\
\text { Ação- } \\
\text { Rev } \\
\text { Acad } \\
\text { do Inst } \\
\text { de } \\
\text { Ciência } \\
\text { s da } \\
\text { Saúde. }\end{array}$ & $\begin{array}{l}\text { SCIE } \\
\text { LO }\end{array}$ & $\begin{array}{l}\text { Barros, } \\
\text { Santos, \& } \\
\text { Jordao, } \\
2019 .\end{array}$ & $\begin{array}{l}\text { Ações do enfermeiro } \\
\text { na prevenção de } \\
\text { infecção por Cateter } \\
\text { Central de Inserção } \\
\text { Periférica em Unidade } \\
\text { de Terapia Intensiva } \\
\text { Neonatal. }\end{array}$ & $\begin{array}{l}\text { Estudo } \\
\text { qualitativo, } \\
\text { descritivo. }\end{array}$ & $\begin{array}{l}\text { Analisar } r \text { dados } \\
\text { estatísticos visando } \\
\text { desenvolver uma } \\
\text { reflexão crítica sobre o } \\
\text { tema, tendo em vista } \\
\text { contribuir para buscar } \\
\text { meios de facilitar o } \\
\text { trabalho desse } \\
\text { profissional. }\end{array}$ & $\begin{array}{l}\text { Faz-se necessário manter os profissionais de } \\
\text { saúde constantemente atualizados, com } \\
\text { investimento na qualificação e capacitações } \\
\text { de enfermeiros e equipe de enfermagem em } \\
\text { geral, abordando procedimento de inserção, } \\
\text { manutenção e remoção do cateter e que } \\
\text { ocorra treinamento para técnicos e auxiliares } \\
\text { de enfermagem quanto os cuidados na } \\
\text { manutenção do cateter, proporcionando } \\
\text { melhor qualidade na assistência prestada ao } \\
\text { neonato na unidade de terapia intensiva. }\end{array}$ \\
\hline $\begin{array}{l}2 \\
9\end{array}$ & $\begin{array}{c}\text { J Res } \\
\text { Funda } \\
\text { m. } \\
\text { Care } \\
\text { Online. }\end{array}$ & $\begin{array}{c}\text { SCIE } \\
\text { LO }\end{array}$ & $\begin{array}{l}\text { Rangel et } \\
\text { al., } 2016 .\end{array}$ & $\begin{array}{l}\text { Cateter Central de } \\
\text { Inserção Periférica em } \\
\text { neonato. }\end{array}$ & $\begin{array}{c}\text { Estudo } \\
\text { qualitativo. }\end{array}$ & $\begin{array}{l}\text { Avaliar acerca das } \\
\text { práticas no uso do } \\
\text { Cateter } \\
\text { Central de Inoso } \\
\text { periférica (PICC) em } \\
\text { Recém-Nascido. }\end{array}$ & $\begin{array}{l}\text { Os profissionais responsáveis pela indicação, } \\
\text { inserção e manutenção do PICC devem } \\
\text { prover cuidados especiais relacionados à } \\
\text { técnica e tecnologias que promovam o } \\
\text { sucesso na inserção do cateter, realizar o } \\
\text { manejo adequado do controle da dor, utilizar } \\
\text { métodos de visualização e posicionamento } \\
\text { ideal da ponta do cateter, adotar medidas } \\
\text { para evitar as principais complicações e para } \\
\text { prevenção de infecção relacionada ao } \\
\text { cateter. }\end{array}$ \\
\hline $\begin{array}{l}3 \\
0\end{array}$ & $\begin{array}{l}\text { Revista } \\
\text { Eletrôn } \\
\text { ica } \\
\text { Acervo } \\
\text { Saúde / } \\
\text { Electro } \\
\text { nic } \\
\text { Journal } \\
\text { Collect } \\
\text { ion } \\
\text { Health. }\end{array}$ & $\begin{array}{c}\text { SCIE } \\
\text { LO }\end{array}$ & $\begin{array}{l}\text { Swerts, } \\
\text { Lima, } \\
\text { Santos, } \\
\text { Rezende, } \\
\text { \& } \\
\text { Macedo, } \\
2020 .\end{array}$ & $\begin{array}{l}\text { A utilização do cateter } \\
\text { central de inserção } \\
\text { periférica em uma } \\
\text { unidade de terapia } \\
\text { intensiva neonatal. }\end{array}$ & $\begin{array}{l}\text { Estudo } \\
\text { quantitativo, } \\
\text { do tipo } \\
\text { epidemiológic } \\
\text { o, descritivo } \\
\text { retrospectivo } \\
\text { de } \\
\text { coorte } \\
\text { simples. }\end{array}$ & $\begin{array}{l}\text { Avaliar a utilização do } \\
\text { cateter central de } \\
\text { inserção periférica } \\
\text { (CCIP) e o caracterizar } \\
\text { o perfil dos neonatos } \\
\text { hospitalizados em uma } \\
\text { unidade de terapia } \\
\text { intensiva neonatal. }\end{array}$ & $\begin{array}{l}\text { O cateter central de inserção periférica foi } \\
\text { utilizado com maior frequência pelos recém- } \\
\text { nascidos do sexo feminino, com diagnóstico } \\
\text { de prematuridade, extremo baixo peso, } \\
\text { síndrome da doença respiratória e infecção } \\
\text { neonatal. O uso deste cateter é } \\
\text { imprescindível para a sobrevivência de } \\
\text { muitos neonatos. }\end{array}$ \\
\hline $\begin{array}{l}3 \\
1\end{array}$ & $\begin{array}{l}\text { Cienc } \\
\text { Cuid } \\
\text { Saúde. }\end{array}$ & $\begin{array}{c}\text { SCIE } \\
\text { LO }\end{array}$ & $\begin{array}{l}\text { Mena, } \\
\text { Silva, } \\
\text { Porto, } \\
\text { Zillmer, } \\
\quad \& \\
\text { Barcello, } \\
2019 .\end{array}$ & $\begin{array}{l}\text { Cateter venoso central } \\
\text { de inserção periférica } \\
\text { em neonatologia: } \\
\text { potencialidades e e } \\
\text { fragilidades na ótica } \\
\text { de enfermeiros. }\end{array}$ & $\begin{array}{l}\text { Estudo } \\
\text { qualitativo, } \\
\text { do tipo } \\
\text { descritivo. }\end{array}$ & $\begin{array}{l}\text { Conhecer } \\
\text { potencialidades as } \\
\text { fragilidades na } \\
\text { utilização do PICC a } \\
\text { partir da ótica dos } \\
\text { enfermeiros. }\end{array}$ & $\begin{array}{l}\text { Eventos adversos decorrentes do uso do } \\
\text { PICC são oriundos da técnica, de obstruções, } \\
\text { de condições inadequadas de integridade ou } \\
\text { manuseio do cateter ou de processos } \\
\text { infecciosos. Deste modo, é indicada a } \\
\text { retirada do dispositivo em casos de } \\
\text { surgimento de sinais flogísticos no sítio de } \\
\text { inserção, ou ao longo do trajeto venoso. }\end{array}$ \\
\hline $\begin{array}{l}3 \\
2\end{array}$ & $\begin{array}{l}\text { Rev } \\
\text { Enferm } \\
\text { UFPE } \\
\text { Online. }\end{array}$ & $\begin{array}{c}\text { SCIE } \\
\text { LO }\end{array}$ & $\begin{array}{c}\text { Silva et } \\
\text { al., } 2016 .\end{array}$ & $\begin{array}{l}\text { Análise da utilização } \\
\text { do cateter central de } \\
\text { inserção periférica em } \\
\text { neonatologia. }\end{array}$ & $\begin{array}{l}\text { Estudo } \\
\text { descritivo, } \\
\text { retrospectivo } \\
\text { quantitativo. }\end{array}$ & $\begin{array}{l}\text { Analisar a utilização } \\
\text { do cateter central de } \\
\text { inserção periférica em } \\
\text { uma unidade de } \\
\text { terapia intensiva } \\
\text { neonatal. }\end{array}$ & $\begin{array}{l}\text { Ao considerar duração do procedimento e a } \\
\text { discreta alteração entre o número de } \\
\text { punções, observa-se maiores dificuldades } \\
\text { para inserção em recém-nascidos com peso } \\
\text { abaixo de } 1,500 \mathrm{~kg} \text {, justificado pela } \\
\text { deficiência da rede venosa. } 9,10,19 \text { Contudo, } \\
\text { para estes, o cateter permaneceu por um } \\
\text { tempo maior, possibilitando o término do } \\
\text { tratamento e a redução da dor e desconforto } \\
\text { decorrente das repetidas punções. }\end{array}$ \\
\hline $\begin{array}{l}3 \\
3\end{array}$ & $\begin{array}{l}\text { Brasil } \\
\text { Para } \\
\text { Todos- } \\
\text { Revista } \\
\text { Interna } \\
\text { cional. }\end{array}$ & $\begin{array}{c}\text { SCIE } \\
\text { LO }\end{array}$ & $\begin{array}{l}\text { Barros, } \\
\text { Diamente } \\
\text { \& Lima, } \\
2019 .\end{array}$ & $\begin{array}{l}\text { Cateter central de } \\
\text { inserção periférica no } \\
\text { Neonato de alto risco, } \\
\text { uma competência do } \\
\text { enfermeiro intensivis - } \\
\text { ta. }\end{array}$ & $\begin{array}{l}\text { Estudo des - } \\
\text { critivo, do ti - } \\
\text { po relato de } \\
\text { caso. }\end{array}$ & $\begin{array}{l}\text { Relatar a experiência } \\
\text { do profissional } \\
\text { enfermeiro na } \\
\text { passagem do Cateter } \\
\text { Central de Inserção } \\
\text { Periférica no paciente } \\
\text { neonatal de alto risco. }\end{array}$ & $\begin{array}{l}\text { A terapêutica intravenosa é de extrema } \\
\text { importância para o neonato de alto risco, no } \\
\text { entanto, a limitação da rede venosa, que o } \\
\text { recém-nascido prematuro apresenta, torna } \\
\text { difícil a prestação de cuidados na terapêutica } \\
\text { endovenosa sendo imprescindível que o } \\
\text { enfermeiro seja capacitado e qualificado para } \\
\text { a realização da técnica de inserção do CCIP. }\end{array}$ \\
\hline
\end{tabular}

Fonte: Autores (2020).

No Quadro 1, tem-se a apresentação dos artigos selecionados para o estudo conforme número do artigo, periódico, base de dados, autor e ano de publicação, título, objetivo, resultados em evidências e conclusões importantes. A partir do estudo dos artigos estabeleceram-se discussões relevantes para observações das produções científicas relacionadas à pesquisa. 
Gráfico 1. Distribuição dos artigos conforme periódico e quantidade.

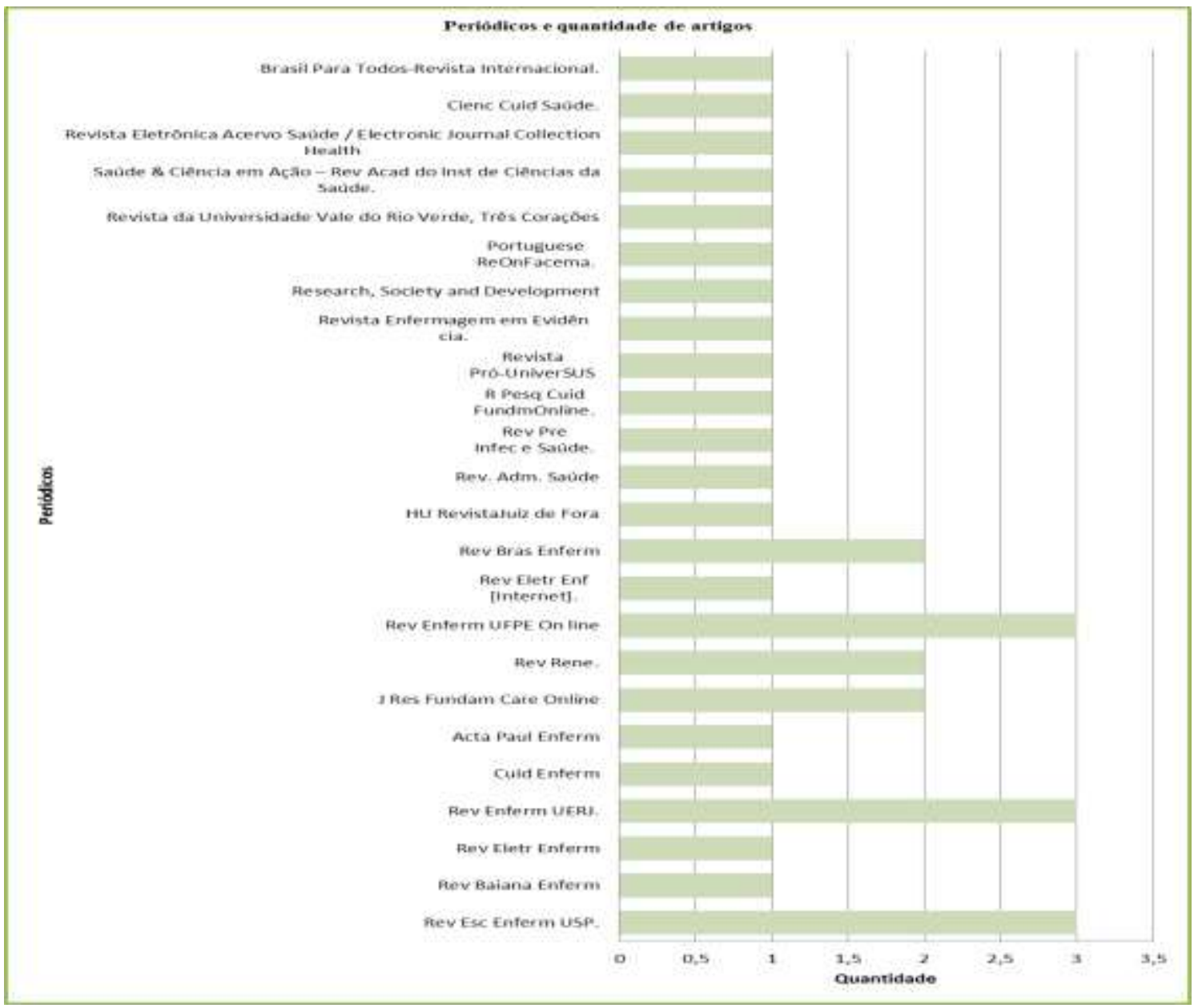

Fonte: Autores (2021).

Segundo o gráfico ilustrado acima, pode-se observar quais são os periódicos e a quantidade de artigos que foram publicados de acordo com a amostra final do referido estudo. Dessa forma, verifica-se que na Rev Esc Enferm USP houve (3) Publicações, Rev Baiana Enferm (1), Rev Eletr Enferm (1), Rev Enferm UFRJ (3), Cuid Enferm (1), Acta Paul Enferm (1), J Res Fundam Care Online (2), Rev Rene (2), Rev Enferm UFPE Online (3), Rev Eletr Enf Internet (1), Rev Bras Enferm (2), HU Revista Juiz de Fora (1), Rev Adm Saúde (1), Rev Pré Infec e Saúde (1) R pesq Cuid Fundm Online (1), Revista PróUniverSUS (1), Revista Enfermagem em Evidências (1), Research, Society and Development (1), Portuguese Reon Facema (1), Revista Universidade Vale do Rio Verde Três Corações (1), Saúde \& Ciência em Ação - Revista Acadêmica do Instituto de Ciências da Saúde (1), Revista Eletrônica Acervo Saúde/Eletronic Journal Collection Health (1), Ciência Cuid Saúde (1), Brasil Para Todos - Revista Internacional (1). 
Research, Society and Development, v. 10, n. 2, e59010212974, 2021

(CC BY 4.0) | ISSN 2525-3409 | DOI: http://dx.doi.org/10.33448/rsd-v10i2.12974

Gráfico 2. Distribuição conforme as bases de dados e a quantidade de artigos.

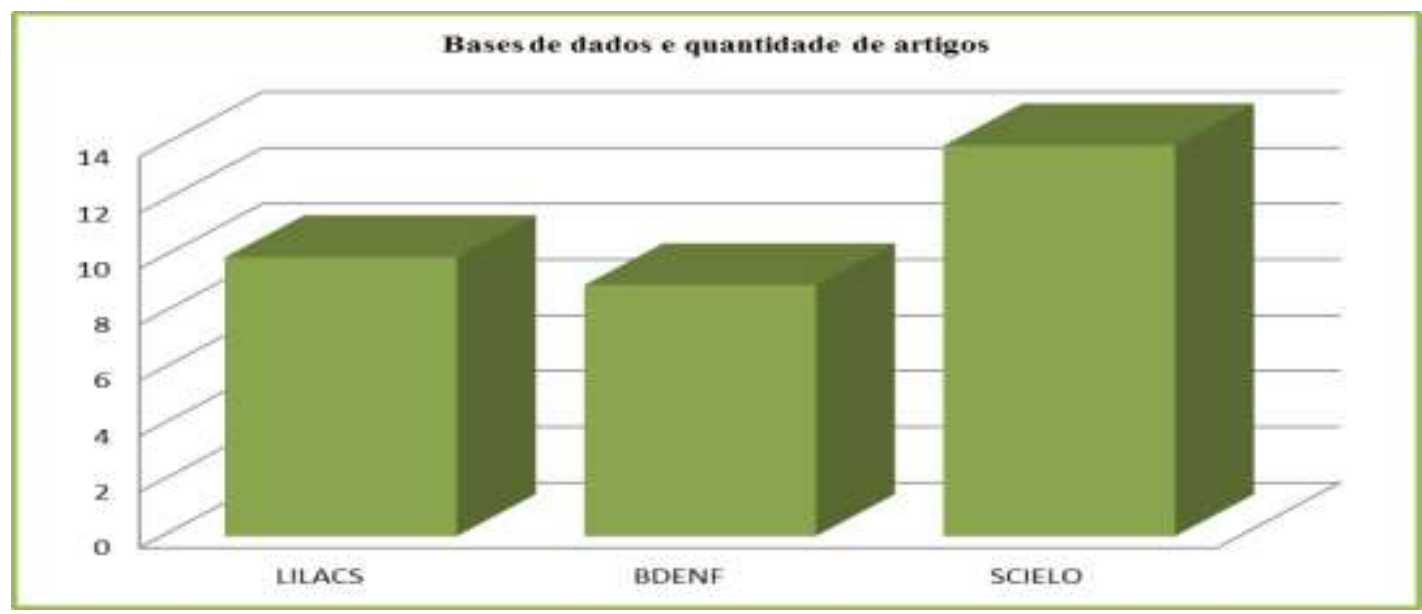

Fonte: Autores (2021).

De acordo com o gráfico representado acima, verifica-se as bases de dados e a quantidade de artigos publicados em cada uma. Nota-se que na LILACS ocorreu (10), publicações, BDENF (9), e na SCIELO (14). Desse modo, totalizando um resultado final de 33 artigos para serem trabalhados na conttrução do presente estudo.

Gráfico 3. Distribuição conforme as bases de dados e a porcentagem de artigos.

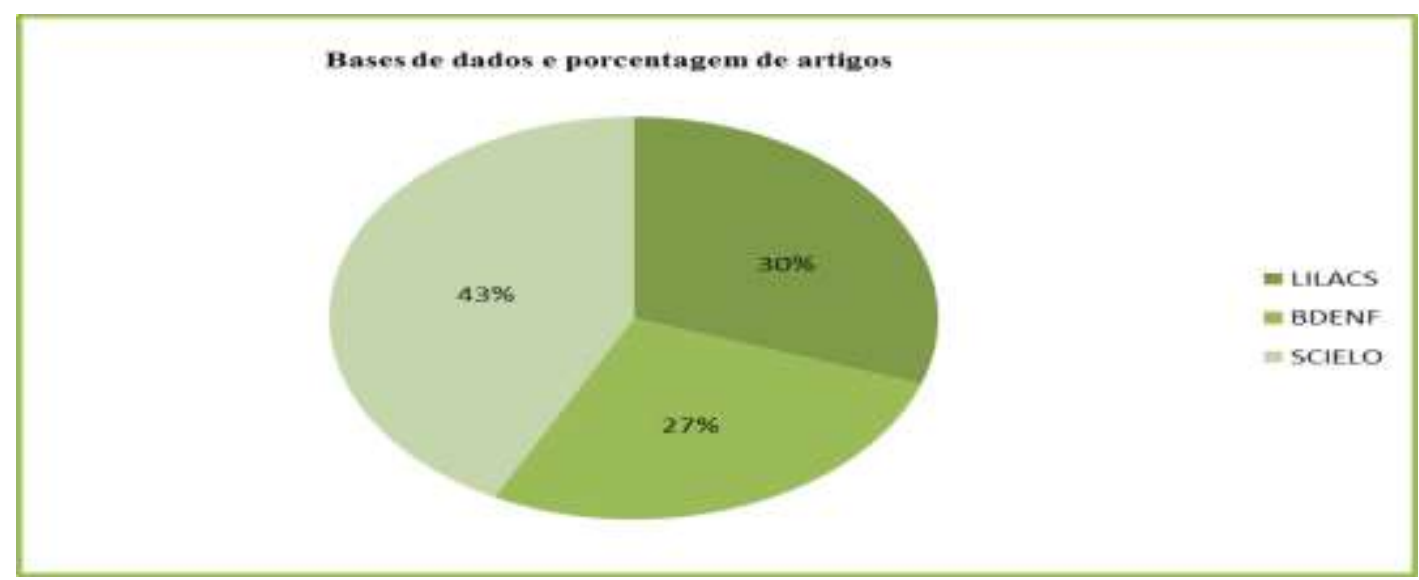

Fonte: Autores (2021).

Ao observar o gráfico acima, percebe-se as bases de dados e a porcentagem de artigos publicados em cada uma, verifica-se que na LILACS ocorreu (30\%) das publicações, BDENF (27\%), e na SCIELO (43\%). Levando a um total geral de 33 artigos (100\%) dos artigos para serem explorados na elaboração do referido estudo. 
Research, Society and Development, v. 10, n. 2, e59010212974, 2021

(CC BY 4.0) | ISSN 2525-3409 | DOI: http://dx.doi.org/10.33448/rsd-v10i2.12974

Gráfico 4. Distribuição dos artigos conforme os anos de publicação e quantidade.

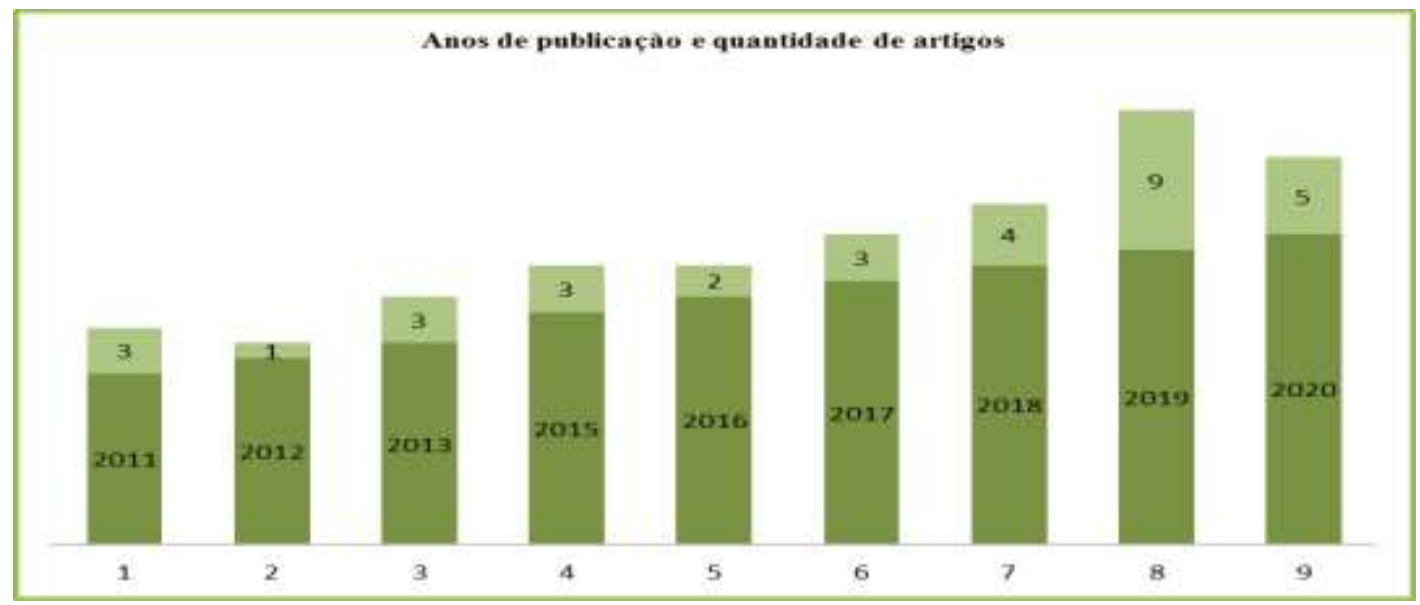

Fonte: Autores (2021).

Ao analisar o gráfico representado acima, identificam-se os anos de publicação e quantidade de artigos publicados. Nota-se que no ano de 2011 houve (3) publicações, 2012 (1), 2013 (3), 2015 (3), 2016 (2), 2017 (3), 2018 (4), 2019 (9), e 2020 (5). Nesse sentido, levando-se ao total final de 33 artigos para comporem a construção de presente estudo.

Gráfico 5. Distribuição dos artigos conforme ano de publicação e porcentagem.

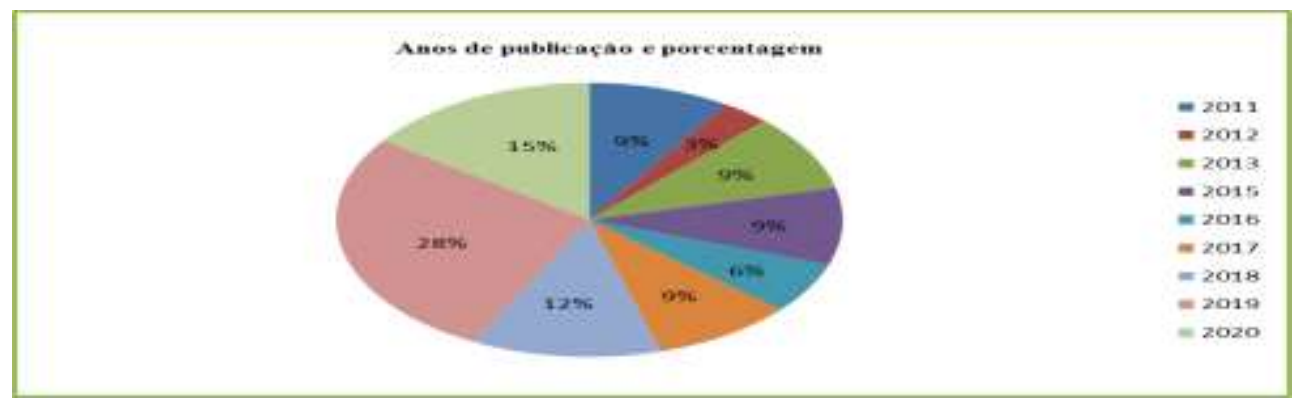

Fonte: Autores (2021).

Segundo o gráfico ilustrado acima, identifica-se os anos de publicação e a porcentagem de artigos encontrados. Constata-se que no ano de 2011 ocorreu (9\%) das publicações, 2012 (3\%), 2013 (9\%), 2015 (9\%), 2016 (6\%), 2017 (9\%), 2018 (12\%), 2019 (28\%), 2020 (15\%). Dessa forma, nota-se que o ano de 2019 houve o maior número de publicações, sendo que, foram adotados os aspectos metodológicos dos critérios de inclusão e exclusão na elaboração do presente estudo. 
Gráfico 6. Distribuição dos artigos conforme o tipo de estudo.

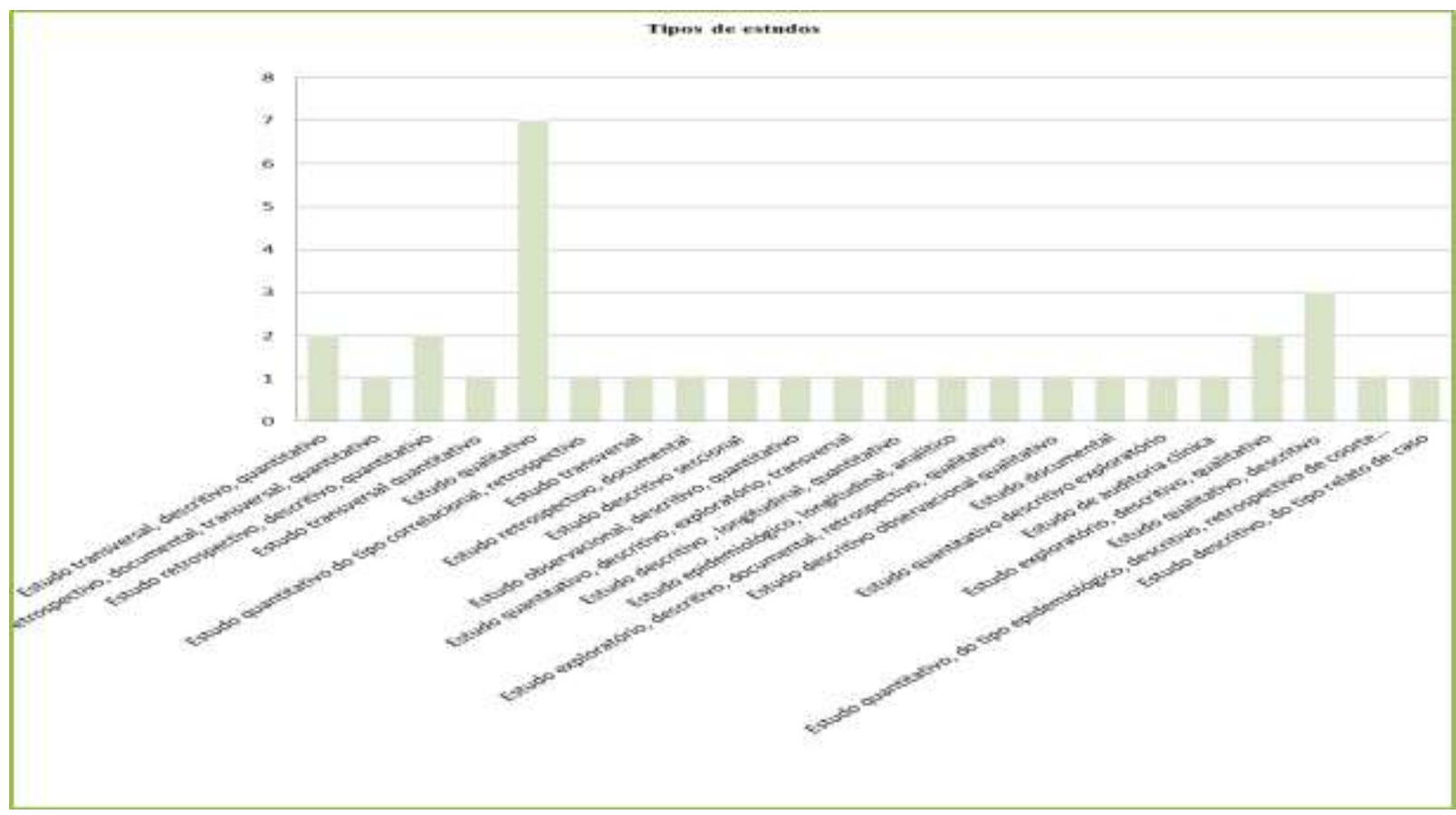

Fonte: Autores (2021).

Diante do gráfico ilustrado acima, percebe-se os tipos de estudos e a quantidade de artigos selecionados na amostra final para compor a elaboração do presente estudo. Dessa forma, encontrou-se um total de: Estudo transversal, descritivo, quantitativo (2), estudo retrospectivo, documental, transversal, quantitativo (1), estudo retrospectivo, descritivo, quantitativo (2), estudo transversal quantitativo (1), estudo qualitativo (7), estudo quantitativo do tipo correlacional, retrospectivo (1), estudo transversal (1), estudo retrospectivo documental (1), estudo descritivo seccional (1), estudo observacional, descritivo, quantitativo (1), estudo quantitativo, descritivo, exploratório, transversal (1), estudo descritivo, longitudinal quantitativo (1), estudo epidemiológico, longitudinal, analítico (1), estudo exploratório, descritivo, documental, retrospectivo, qualitativo (1), estudo descritivo, observacional, qualitativo (1), estudo documental (1), estudo quantitativo, descritivo, exploratório (1), estudo de auditoria clínica (1), estudo exploratório, descritivo, qualitativo (2), estudo qualitativo, descritivo (3), estudo quantitativo, do tipo epidemiológico, descritivo, retrospectivo de coorte simples (1), estudo descritivo do tipo relato de caso (1).

A utilização do Cateter Venoso Central de Inserção Periférica principalmente em Unidade de Terapia Intensiva Neonatal é uma conquista de enfermagem constituída por uma trajetória de esforços que conduziu um novo desafio para o aperfeiçoamento desta prática, tendo o profissional de enfermagem competência técnica e legal para exercer a prática de manipulação do cateter. Importante destacar que se trata de um procedimento invasivo, com rigorosa assepsia na inserção e à manipulação do mesmo. Sabe-se que o uso de cateteres venosos centrais em Unidades de Terapia Intensiva Neonatal é uma prática comum e não está isento de complicações, mesmo com todo o rigor da assepsia, o que se deve a vários fatores de riscos associados (Swerts, Lima, Santos, Rezende, \& Macedo, 2020).

Segundo Rangel (2019), a terapia intravenosa é uma das áreas que tem demandado cuidado da assistência de enfermagem em neonatologia, devido à constante necessidade de acesso venoso seguro e duradouro para administração de antibióticos, hidratação venosa, nutrição parenteral, drogas vasoativas entre outras. Para que haja sucesso na prática clínica com o PICC alguns fatores devem ser considerados, como a habilidade e capacitação técnica do profissional enfermeiro, conhecimento sobre o cateter, indicação, contraindicação, eleição do vaso que será puncionado, técnica de inserção, 
complicações, bem como, cuidados específicos para inserção, manutenção e remoção ao final da indicação terapêutica (Sá Neto, 2018).

As principais indicações para uso do PICC são os recém-nascidos que necessitem de terapia intravenosa por um período superior a seis dias, utilização de medicações (principalmente antibióticos, quimioterápicos, soluções vesicantes e hiperosmolares), nutrição parenteral prolongada ou outras terapias intravenosas de longa permanência. Os benefícios são a longa permanência do dispositivo, redução da ocorrência de pneumotórax e hemotórax, custo financeiro inferior ao do cateter venoso central inserido cirurgicamente, redução do número de punções venosas periféricas e, consequentemente, otimização do tempo do profissional de enfermagem. Outros benefícios são as chances reduzidas de infecção em comparação com o cateter venoso central, proteção da rede venosa, inserção menos lesiva, tempo de utilização aumentado, possibilidade de administrar soluções irritantes e/ou vesicantes, redução dos custos para os serviços de saúde, garantia de segurança ao paciente, além da realização do procedimento de inserção à beira leito realizado pelo enfermeiro (Mittang, Stiegler, Kroll, \& Schultz, 2020).

Dessa forma, a tecnologia do PICC contribui de maneira expressiva na assistência humanizada e especializada para os que necessitam de terapia endovenosa, evitando múltiplos procedimentos de punção venosa que podem potencializar o trauma, estresse e a dor do recém-nascido e da criança hospitalizada, além das repercussões emocionais também na família. Esse dispositivo intravenoso, embora importantíssimo para garantir a sobrevivência do recém-nascido e da criança, necessita além da capacitação profissional, materiais específicos e monitorização. Todavia, não está isento de complicações, tais como fratura do cateter, infecção da corrente sanguínea, flebite, hematomas, mau posicionamento com risco de infiltração, extra-vasamento, tamponamento cardíaco e arritmia cardíaca, os quais podem resultar em punções recorrentes que facilitam o trauma em vasos sanguíneos (Mittang, Stiegler, Kroll, \& Schultz, 2020).

O uso do cateter na UTI neonatal é representativo, e o enfermeiro tem papel fundamental durante todo o processo de utilização para evitar as complicações. O enfermeiro necessita ter conhecimento dos motivos que levam à retirada antecipada do dispositivo anterior ao término do tratamento e, posteriormente, desenvolver e implementar protocolos e estratégias de cuidados ampliadas. O manuseio adequado, capacitado e o reconhecimento dos sinais e sintomas dessas alterações são fundamentais durante a assistência ao recém-nascido (Mittang, Stiegler, Kroll, \& Schultz, 2020).

As punções venosas periféricas e o uso de dispositivos invasivos são práticas frequentes nos ambientes de cuidado em saúde, e apresentam grande risco de infecções relacionadas à assistência à saúde que podem prolongar as internações em Unidades de Terapia Intensiva. Assim, (INS), são realizadas, anualmente, milhões de punções venosas periféricas, podendo o uso do cateter venoso periférico originar complicações relacionadas a diversos fatores de risco. Deste modo, destacam-se as falhas relacionadas à manutenção de cateteres que podem chegar a 69,0\% dos casos, necessitando de novo processo de punções venosas para inserção de cateter venoso periférico, com finalidade de completar a terapêutica, podendo resultar em infecções relacionadas à assistência à saúde. Nesse sentido, a manipulação adequada dos cateteres diminui o risco de infecção. Logo, recomenda-se a utilização de protocolos institucionais validados e a aplicação conjunta de medidas preventivas "Bundles", visando reduzir as infecções primárias de corrente sanguínea. O bundle relacionado ao cateter venoso periférico de medidas da Agência Nacional de Vigilância Sanitária compreende cinco componentes: 1- higienização das mãos; 2- precaução de barreira máxima; 3- preparo da pele com gluconato de clorexidine; 4- seleção de sítio de inserção; e 5 - revisão diária da necessidade de permanência do cateter (Lanza et al., 2019).

De acordo com Borghesan et al. (2017), o PICC é um cuidado tecnológico realizado por enfermeiros, o qual proporciona ao neonato inúmeros benefícios como a otimização da assistência intravenosa sem a interrupção do tratamento; prevenção de flebites por extravasamento; preservação do sistema venoso periférico; redução do estresse da equipe de enfermagem e do RN por punções venosas. O procedimento para instalação do PICC deve ser feito quando a rede venosa ainda 
está preservada, uma vez que a presença de edema, eritema, hematoma, ou lesão cutânea, causados por punções venosas anteriores, dificultam a progressão do cateter. O processo para instalação do PICC deve ocorrer à beira do leito e com técnica de barreira máxima. Outros cuidados para proceder com a inserção é a monitorização cardíaca do RN e manejo da dor (Borghesan et al., 2017).

A manutenção do PICC exige cuidados, recomenda-se que em pacientes pediátricos, a troca do curativo seja realizada somente se estiver descolando, apresentarem sujidade, umidade ou sangramento, não havendo um prazo determinado, uma vez que em pediatria o risco de deslocamento do PICC é maior que o benefício da troca. Vale evidenciar que a confecção do curativo é atividade privativa do enfermeiro que recebeu capacitação, pois este profissional será capaz de identificar possíveis complicações, apresentando habilidade técnica para prevenir deslocamento e infecção do PICC pela manipulação. A permeabilização com soro fisiológico deve acontecer antes e após a infusão de medicamentos e a cada 6 horas, para evitar a obstrução. É indicada a utilização apenas de seringas com volume igual ou superior a 10 mililitros, pois volumes inferiores podem causar rompimento e embolia do lúmen do cateter (Borghesan et al., 2017).

Deve-se adotar medidas preventivas de infecção de corrente sanguínea (ICS) relacionada ao cateter, tais como: barreira máxima na inserção, higienizar as mãos antes e após a manipulação do PICC; realizar a desinfecção das conexões e do hub com álcool à 70\% antes da infusão de qualquer solução; substituir periodicamente o sistema infusional (equipo, polifix,) conforme rotina estabelecida pelo fabricante ou pela unidade; proteger o PICC e as conexões durante o banho e remover o PICC tão logo não seja mais necessário. A identificação precoce de complicações pelo enfermeiro é extremamente importante, devendo o mesmo observar periodicamente o óstio de inserção do cateter com vistas a identificar presença de rubor, secreção e sinais de desalojamento. Também deve estar atento à hipertermia, aparecimento de flebite, celulite bem como fratura e obstrução do dispositivo. Não é recomendada a substituição rotineira do PICC com vistas a prevenir ICS relacionada ao cateter, tampouco sua remoção devido apenas a febre (Borghesan et al., 2017).

Deve-se lançar mão de julgamento clínico para avaliar a probabilidade de infecção em outro sitio. A retirada do dispositivo pode ocorrer devido à finalização da terapia; posicionamento inadequado; presença de sinais flogísticos no local de inserção ou ao longo do percurso da veia; trombose no membro do acesso; febre ou hipotermia sem outro foco de infecção evidente; quebra ou ruptura; oclusão irreversível; extravasamento de soluções ou presença de foco infeccioso ou inflamatória. Vale destacar a necessidade de inspecionar a integridade da ponta do PICC no ato da remoção e checar se o comprimento retirado é compatível com o inserido (Borghesan et al., 2017).

Com relação ao tempo de permanência desse tipo de acesso, o recomendado é que seja mantido até o final da terapia intravenosa, exceto em situações em que ocorram o aparecimento de sinais flogísticos no sítio de inserção ou ao longo do trajeto venoso, trombose ou obstrução. A manutenção do PICC exige um manuseio adequado da equipe de enfermagem e requer o uso de um curativo ideal. Este curativo deverá promover maior permanência do cateter durante a terapia, pois a estabilização inadequada pode levar a perda do dispositivo. O curativo do dispositivo PICC tem duas funções fundamentais, a de proporcionar ao local de inserção um ambiente protegido, e a de evitar que o cateter migre ou se desloque para os locais inadequados (Vera, Sousa, \& Araújo, 2015).

Dentre os cuidados fundamentais na implantação do PICC em neonatos podemos citar: monitorização cardiorrespiratória, a sedação e analgesia como estratégia de prevenção da dor. O RN deve estar posicionado em decúbito dorsal, mantendo membro superior direito em ângulo de $90^{\circ}$ em relação ao tórax, mensurar com fita métrica o local de inserção do cateter até a altura da clavícula, e desse ponto até o $3^{\circ}$ espaço intercostal direito onde a ponta do cateter deve ser visualizada radiograficamente no terço distal da veia cava superior. Durante a inserção o profissional deverá utilizar precauções máximas de barreiras: máscara, gorro, avental estéril, luvas e campos estéreis. Para anti-sepsia cutânea há indicação de clorexidina como anti-séptico de primeira escolha, no entanto não há evidências relativas à comparação entre clorexidina, tintura de iodo e álcool 
70\%. Deve-se aguardar a secagem do antisséptico antes da punção. A cada manipulação do cateter as mãos devem ser rigorosamente higienizadas (Vera, Sousa, \& Araújo, 2015).

A utilização do PICC, é uma inovada tecnologia necessária em neonatalogia, está se tornando um procedimento comum a prática dos enfermeiros nas unidades de alto risco neonatal. Para isto, o manuseio deste dispositivo requer conhecimento, destreza e habilidade, priorizando o cuidado com a manutenção do cateter. Além disso, devem conhecer os riscos aos quais os recém-nascidos submetidos a tal procedimento estão expostos, a fim de utilizarem medidas de prevenção, controle e detecção das possíveis complicações os quais serão responsabilizados. Assim, pode-se afirmar que, o enfermeiro desempenha um papel fundamental, junto à equipe assistencial em neonatalogia, porém, ele deve estar capacitado a exercer atividades de maior complexidade, respaldado em conhecimentos científicos concretizados a partir da prática cotidiana de cuidar e da pesquisa, a fim de conduzir um atendimento com autoconfiança, e segurança (Sirqueira, \& Souza, 2017).

Dessa forma, compete ao enfermeiro atualizar periodicamente os conhecimentos a respeito das diretrizes e competência para inserir e manipular cateteres, tendo em ênfase os cuidados com a manutenção do PICC, delegando essas funções apenas a profissionais competentes para tal função, ressaltando seu papel de educador, padronizando protocolos e disseminando saberes (Sirqueira, \& Souza, 2017).

\section{Conclusão}

Evidenciou-se no estudo, que a inserção e manuseio do PICC exigem da equipe de enfermagem uma adequada capacidade técnica e científica para que haja uma assistência de forma segura e eficaz. Ressalta-se que é uma prática de grande complexidade, e que o profissional envolvido na assistência deve adquirir conhecimento teórico-prático e incorpora-los na sua prática, acrescidos de seu conhecimento profissional, pois sendo o dispositivo um de longa permanência, o manuseio inadequado e a falta de treinamento da equipe de enfermagem são fatores que conduzem a perda do cateter e potencializam os riscos e complicações.

Dessa forma, o Cateter Venoso de Inserção Periférica é um grande avanço tecnológico para uma Unidade de Terapia Intensiva Neonatal, tendo o diferencial ao amenizar os excessos de tentativas de punções, diminuindo assim, a agressividade com a pele do RN, não causando dor, reduzindo as tentativas de acessos venosos periféricos, proporcionando melhor hidratação venosa e tratamento, sem interrupções de antibioticoterapia estabelecida. Assim, o PICC é responsável por um resultado positivo, que é a grande eficácia em sua utilização, em virtude do maior tempo de permanência no RN prematuro, sem a necessidade de trocar a cada 96 horas, como relata o protocolo da ANVISA, menor risco de flebite química, dentre outros. É imprescindível que toda a equipe se conscientize que para o PICC alcançar seus benefícios, é necessário autoconsciência e conhecimento acerca do seu manuseio de acordo com o protocolo necessário, pois assim a manipulação será da forma correta, gerando uma maior durabilidade.

Diante desse contexto, destaca-se a necessidade do PICC ser a via de primeira escolha para terapia intravenosa, com vistas à minimização do estresse e dor ao neonato, à diminuição do número de punções venosas e ao estabelecimento de um acesso duradouro e de fácil manuseio, reconhecendo potencialidades acerca do uso do dispositivo. Torna-se importante a realização de estudos futuros com a finalidade de ampliar a produção científica a respeito dessa temática tão relevante, sendo de suma importância, no sentido de aprofundar discussões que possam contribuir para a promoção da saúde e na melhoria da qualidade de vida desses pacientes.

\section{Referências}

Araújo Barros, F. C., dos Santos, S. C., \& da Cunha Jordão, C. (2019). Ações do enfermeiro na prevenção de infecção por Cateter Central de Inserção Periférica em Unidade de Terapia Intensiva Neonatal F. Saúde \& Ciência em Ação, 5(1), 54-62. 
Baggio, M. A., Cheffer, M. H., Luz, M. A. P. D., Sanches, M. D. M., \& Berres, R. (2019). Utilização do Cateter Central de Inserção Periférica em neonatos: análise da indicação à remoção.

Barbosa, C. V., Canhestro, M. R., Couto, B. R. G. M., Guimarães, G. D. L., Quispe Mendoza, I. Y., \& Goveia, V. R. (2017). Saberes da equipe de enfermagem sobre cuidados com Cateter Venoso Central. Rev. enferm. UFPE on line, 4343-4350.

Barbosa, J. P. (2011). A importância do enfermeiro no manuseio do PICC na Unidade de Terapia Intensiva Neonatal. Revista de Pesquisa Cuidado é Fundamental Online, 3(2), 1827-1834.

Barros, L., \& Diamente, L. (2019). Cateter central de inserção periférica no neonato de alto risco, uma competência do enfermeiro intensivista. Brasil Para Todos-Revista Internacional, 7(1), 95-103.

Bomfim, J. M. S., Passos, L. D. S., Santos, F. S., Santos, L. H. D., \& Silva, J. C. D. (2019). Desafios na manutenção do Cateter Central de Inserção Periférica em neonatos. CuidArte, Enferm, 174-179.

Borges, T. B. R. D. (2018). Atuação do enfermeiro frente ao risco de infecção com cateter venoso central na Unidade de Terapia Intensiva.

Borghesan, N. B. A., Demitto, M. O., Fonseca, L. M. M., Fernandes, C. A. M., Costenaro, R. G. S., \& Higarashi, I. H. (2017). Cateter Venoso Central de Inserção Periférica: práticas da equipe de enfermagem na atenção intensiva neonatal [Peripherally inserted central catheter: practics of nursing team in the neonatal intensive care][Catéter central de inserción periférica: práctica del equipo de enfermería en la atención intensiva neonatal]. Revista Enfermagem UERJ, 25, 28143

Botelho, L. L. R., de Almeida Cunha, C. C., \& Macedo, M. (2011). O método da revisão integrativa nos estudos organizacionais. Gestão e sociedade, 5(11), 121-136.

Costa Cavalcante, R., Marques, A. D. B., de Oliveira Branco, J. G., do Couto, C. S., Campos, A. D. C. S., \& Rolim, K. M. C. (2015). Cuidados de enfermagem na manutenção do Cateter Central de Inserção Periférica em neonatos. Revista Prevenção de Infecção e Saúde, 1(2), 64-74.

Costa, C. A. B., Araújo, F. L., Costa, A. C. L., Corrêa, A. D. R., Kusahara, D. M., \& Manzo, B. F. (2020). Bundle de Cateter Venoso Central: conhecimento e comportamento de profissionais em Unidades de Terapia Intensiva adulto. Rev. Esc. Enferm. USP, e03629-e03629.

Dórea, E., Castro, T. E. D., Costa, P., Kimura, A. F., \& Santos, F. G. D. (2011). Práticas de manejo do cateter central de inserção periférica em uma unidade neonatal. Revista Brasileira de Enfermagem, 64(6), 997-1002.

Duarte, E. D., Pimenta, A. M., Silva, B. C. N., \& Paula, C. M. D. (2013). Fatores associados à infecção pelo uso do cateter central de inserção periférica em Unidade de Terapia Intensiva Neonatal. Revista da Escola de Enfermagem da USP, 47(3), 547-554.

Ercole, F. F., Melo, L. D., \& Alcoforado, C. L. G. C. (2014). Revisão integrativa versus revisão sistemática. Rev Min Enferm, 18(1), 9-12.

Ferreira, C. P., Querido, D. L., Christoffel, M. M., de Almeida, V. S., Andrade, M., \& Leite, H. C. (2020). A utilização de Cateteres Venosos Centrais de Inserção Periférica na Unidade Intensiva Neonatal. Revista Eletrônica de Enfermagem, 22.

Gomes, A. V. D. O., \& Nascimento, M. A. D. L. (2013). O processo do cateterismo venoso central em Unidade de Terapia Intensiva Neonatal e Pediátrica. Revista da Escola de Enfermagem da USP, 47(4), 794-800.

Lanza, V. E., Alves, A. P. P., Camargo, A. M. S., Cacciari, P., Montandon, D. S., \& Godoy, S. D. (2019). Medidas preventivas de infecção relacionada ao cateter venoso periférico: adesão em terapia intensiva.

Mena, L. S., da Silva, R. C., Porto, A. R., Zillmer, J. G. V., \& Barcellos, C. R. B. (2019). < b > Cateter venoso central de inserção periférica em neonatologia: potencialidades e fragilidades na ótica de enfermeiros/Peripherally inserted of central catheter of in neonatology: potentials and fragilities according to nurses' perspective< b. Ciência, Cuidado e Saúde, 18(4).

Mendes, K. D. S., Silveira, R. C. D. C. P., \& Galvão, C. M. (2008). Revisão integrativa: método de pesquisa para a incorporação de evidências na saúde e na enfermagem. Texto \& contexto enfermagem, 17(4), 758-764.

Mingorance, P., Johann, D. A., Lazzari, L. S. M. D., Pedrolo, E., \& Danski, M. T. R. (2013). Relações significativas acerca do cateter central de inserção periférica. Rev. enferm. UFPE on line, 1295-1300.

Mittang, B. T., Stiegler, G., Kroll, C., \& Schultz, L. F. (2020). Cateter Central de Inserção Periférica em recém-nascidos: fatores de retirada. Rev. baiana enferm, $\mathrm{e} 38387-\mathrm{e} 38387$.

Neves Motta, P., Fialho, F. A., Dias, I. M. Á. V., \& do Nascimento, L. (2011). Cateter central de inserção periférica: o papel da enfermagem na sua utilização em neonatologia. HU Revista, 37(2).

Pereira, A. S., Shitsuka, D. M., Parreira, F. J., \& Shitsuka, R. (2018). Metodologia da pesquisa científica.

Prado, N. C. D. C., Santos, R. S. D. C., Lima, D. M. D., Góis, M. M. D. C. D., Costa, R. H. S., \& Silva, R. A. R. D. (2019). Necessidades humanas básicas alteradas em neonatos com cateter central de inserção periférica. Rev. enferm. UERJ, e44521-e44521.

Rangel, R. J. M., Castro, D. S. D., Amorim, M. H. C., Zandonade, E., Christoffel, M. M., \& Primo, C. C. (2019). Práticas de inserção, manutenção e remoção do Cateter Central de Inserção Periférica em neonatos. Rev. pesqui. cuid. fundam. (Online), 278-284.

Rangel, R. J. M., de Castro, D. S., Primo, C. C., Zandonade, E., Christoffel, M. M., \& Amorim, M. H. C. (2016). Cateter Central de Inserção Periférica em neonato. Revista de Pesquisa: Cuidado é fundamental online, 8(4), 5193-5202.

Ribeiro, A. M. N., da Costa, G. O. P., Leite, Y. M. R., dos Santos Pereira, E., de Sousa, J. C. R., Rodrigues, L. M. C., ... \& da Cruz, F. M. P. (2020). Prevenção de infecção relacionada à Cateter Venoso Central: cuidados e conhecimento da equipe de enfermagem. Research, Society and Development,9(11), e93091110711-e93091110711. 
Research, Society and Development, v. 10, n. 2, e59010212974, 2021

(CC BY 4.0) | ISSN 2525-3409 | DOI: http://dx.doi.org/10.33448/rsd-v10i2.12974

Ribeiro, W. A., Andrade, M., Fassarella, B. P. A., de Melo Pereira, V., Pereira, E. R., Cirino, H. P., \& de Azevedo, T. D. P. (2018). Cateter venoso central na UTI pediátrica: o enfermeiro intensivista na prevenção e controle das infecções hospitalares. Revista Pró-UniverSUS, 9(2), 47-52.

Sá Neto, J. A. D., Silva, A. C. S. S. D., Vidal, A. R., Knupp, V. M. D. A. O., Barcia, L. L. D. C., \& Barreto, A. C. M. (2018). Conhecimento de enfermeiros acerca do cateter central de inserção periférica: realidade local e desafios globais. Rev. enferm. UERJ, e33181-e33181.

Secoli, S. R., \& de Jesus, V. C. (2007). Complicações acerca do cateter venoso central de inserção periférica (PICC). Ciência, cuidado e saúde, 6(2), $252-260$.

Silva, M. P. C., Bragato, A. G. D. C., Ferreira, D. D. O., Zago, L. B., Toffano, S. E. M., Nicolussi, A. C., \& Amaral, J. B. D. (2019). Bundle for handling peripherally inserted central catheter in newborns. Acta Paulista de Enfermagem, 32(3), 261-266.

Silva, R. M. M., Lui, A. M., Ferreira, H., Franca, A. F. O., Lala, E. R. P., \& Viera, C. S. (2016). Análise da utilização do Cateter Central de Inserção Periférica em neonatologia. Revista de Enfermagem UFPE on line [Internet], 10, 796-804.

Sirqueira, L. A., \& Souza, K. F. (2017). Cuidados de enfermagem na manutenção do Cateter Central de Inserção Periférica no recém-nascido. Revista da Universidade Vale do Rio Verde, 15(1), 139-151.

Soares, C. B., Hoga, L. A. K., Peduzzi, M., Sangaleti, C., Yonekura, T., \& Silva, D. R. A. D. (2014). Revisão integrativa: conceitos e métodos utilizados na enfermagem. Revista da Escola de Enfermagem da USP, 48(2), 335-345.

Sousa, F. C., Pereira, J. C., de Andrade Rezende, D., \& Laura, C. (2018). Avaliação dos cuidados de enfermagem com o cateter venoso central em uma unidade de terapia intensiva adulto e pediátrica. Revista de Administração em Saúde, 18(70).

Sousa, L. M. M., Marques-Vieira, C. M. A., Severino, S. S. P., \& Antunes, A. V. (2017). A metodologia de revisão integrativa da literatura em enfermagem. No21 Série 2-Novembro 2017, 17.

Souza, M. T. D., Silva, M. D. D., \& Carvalho, R. D. (2010). Revisão integrativa: o que é e como fazer. Einstein, 8(1), 102-106.

Swerts, C. A. S., de Lima, C. C., de Fátima Santos, A., de Jesus Rezende, E., \& Macedo, F. R. M. (2020). A utilização do cateter central de inserção periférica em uma unidade de terapia intensiva neonatal. Revista Eletrônica Acervo Saúde, (40), e2268-e2268.

Swerts, C. A. S., Felipe, A. O. B., de Miranda Rocha, K., \& Andrade, C. U. B. (2013). Cuidados de enfermagem frente às complicações do cateter central de inserção periférica em neonatos. Revista Eletrônica de Enfermagem, 15(1), 156-61.

Vera, S. O., de Sousa, G. N., \& Mesquita, S. N. (2015). A atuação do enfermeiro na prática de inserção e manutenção do PICC: uma revisão integrativa de literatura. Revista Ciência \& Saberes-UniFacema, 1(1), 47-53. 